\title{
A Comprehensive Review of Prone Position in ARDS
}

\author{
Richard H Kallet MSc RRT FAARC
}

\author{
Introduction \\ Effects of PP on Chest Mechanics \\ Ventilation/Perfusion Relationship \\ Distribution of Ventilation in PP \\ Pulmonary Perfusion in PP \\ Airway Closure and Ventilation/Perfusion Matching in Experimental \\ ARDS and PEEP During PP \\ Effects of PP on Oxygenation in ARDS \\ Prevalence of Positive Oxygenation Response \\ Magnitude of Oxygenation Response \\ Temporal and Etiological Aspects of Oxygenation Response \\ Alveolar Ventilation and Recruitment During PP in ARDS \\ Effects of PP on Airway Secretion Clearance and \\ Ventilator-Associated Pneumonia \\ Effects of PP on Alveolar Fluid Clearance \\ Hemodynamic Effects of PP \\ Hemodynamic Effects of Intra-Abdominal Pressure During PP \\ Effects of PP on Right Heart Function in ARDS \\ Effects of PP in Acute Brain Injury \\ Effects of PP on Ventilator-Induced Lung Injury in \\ Experimental and Clinical ARDS \\ Randomized Controlled Trials of PP \\ Meta-Analysis of Randomized Controlled Trials \\ Adverse Events Associated With PP \\ Incorporating PP into Bundled Care \\ High-Level PEEP and Recruitment Maneuver \\ Inhaled Vasodilators \\ Extracorporeal Membrane Oxygenation \\ Practical Considerations: Indications, PEEP Strategy, Deescalating \\ Therapy \\ Manual Versus Automated PP \\ Incorporating Continuous Rotational Therapy With PP \\ Summary
}

Prone position (PP) has been used since the 1970s to treat severe hypoxemia in patients with ARDS because of its effectiveness at improving gas exchange. Compared with the supine position (SP), placing patients in PP effects a more even tidal volume distribution, in part, by reversing the vertical pleural pressure gradient, which becomes more negative in the dorsal regions. PP also improves resting lung volume in the dorsocaudal regions by reducing the superimposed pressure of both the heart and the abdomen. In contrast, pulmonary perfusion remains preferentially distributed to the dorsal lung regions, thus improving overall alveolar ventilation/perfusion relationships. 


\begin{abstract}
Moreover, the larger tissue mass suspended from a wider dorsal chest wall effects a more homogeneous distribution of pleural pressures throughout the lung that reduces abnormal strain and stress development. This is believed to ameliorate the severity or development of ventilator-induced lung injury and may partly explain why PP reduces mortality in severe ARDS. Over 40 years of clinical trials have consistently reported improved oxygenation in approximately $70 \%$ of subjects with ARDS. Early initiation of PP is more likely to improve oxygenation than initiation during the subacute phase. Maximal oxygenation improvement occurs over a wide time frame ranging from several hours to several days. Meta-analyses of randomized controlled trials suggest that PP provides a survival advantage only in patients with relatively severe ARDS $\left(\mathrm{P}_{\mathrm{aO}_{2}} / \mathrm{F}_{\mathrm{IO}_{2}}<150 \mathrm{~mm} \mathrm{Hg}\right)$. Moreover, survival is enhanced when patients are managed with a smaller tidal volume ( $\leq 8 \mathrm{~mL} / \mathrm{kg}$ ), higher PEEP (10-13 $\mathrm{cm} \mathrm{H}_{2} \mathrm{O}$ ), and longer duration of PP sessions ( $>10-12 \mathrm{~h} / \mathrm{session}$ ). Combining adjunctive therapies (high PEEP, recruitment maneuvers, and inhaled vasodilators) with PP has an additive effect in improving oxygenation and may be particularly helpful in stabilizing gas exchange in very severe ARDS. Key words: ARDS; acute lung injury; prone position; transpulmonary pressure; ventilation/perfusion ratios; recruitment maneuvers; ventilator-induced lung injury [Respir Care 2015;60(11):1660-1687. (C) 2015 Daedalus Enterprises]
\end{abstract}

\section{Introduction}

Prone position (PP) has been used since the 1970s to treat severe hypoxemia in patients with ARDS..$^{1-3}$ Mellins ${ }^{1}$ observed that in advanced cystic fibrosis, children spontaneously position themselves on their hands and knees to improve ventilation. A concurrent study reported that passive mechanical ventilation in the supine position (SP) resulted in ventilation distributed primarily to nondependent lung regions where perfusion was reduced. ${ }^{4}$ Based on the recognition that acute respiratory failure is associated with diminished functional residual capacity (FRC) and that SP enhances dependent airway closure, Bryan ${ }^{5}$ suggested that PP might recruit and stabilize dependent lung segments. Two subsequent small case studies of ARDS reported mean $\mathrm{P}_{\mathrm{aO}_{2}}$ increased by 47 and $53 \mathrm{~mm} \mathrm{Hg}$ when positioning was changed from SP to PP. ${ }^{2,3}$

Despite numerous observational and randomized controlled trials (RCTs) demonstrating the effectiveness of PP in improving oxygenation, this did not translate into im-

\footnotetext{
Mr Kallet is affiliated with Respiratory Care Services, Department of Anesthesia, University of California, San Francisco at San Francisco General Hospital, San Francisco, California.

Mr Kallet presented a version of this paper at the 30th New Horizons Symposium at the AARC Congress 2014, held December 9-12, 2014 in Las Vegas, Nevada.

Supplementary material related to this paper is available at http: //www.rcjournal.com.
}

Correspondence: Richard H Kallet MSc RRT FAARC, Respiratory Care Services, San Francisco General Hospital, NH:GA-2, 1001 Potrero Avenue, San Francisco, CA 94110. E-mail: rich.kallet@ucsf.edu.

DOI: $10.4187 /$ respcare.04271 proved outcomes. However, the recent publication of the landmark PROSEVA study ${ }^{6}$ and consistent results of numerous meta-analyses of RCTs $\mathrm{s}^{7-13}$ now demonstrate a clear mortality reduction when PP is applied early and for prolonged time periods in subjects with severe ARDS. This represents the most significant advance in the management of ARDS since the seminal ARDS Net trial ${ }^{14}$ of low tidal volume $\left(\mathrm{V}_{\mathrm{T}}\right)$ ventilation over a decade ago. Because $\mathrm{PP}$ is likely to become commonplace in the management of severe ARDS, this comprehensive review is intended to serve both as a resource for clinicians wishing to gain a better understanding of the physiologic principles upon which PP is based and as a detailed examination of its effects on gas exchange, hemodynamics, ventilator-induced lung injury (VILI), and outcomes based upon 40 years of clinical evidence.

This review first focuses on the physiologic principles explaining how patient positioning impacts lung and chest mechanics and alveolar ventilation/perfusion $\left(\mathrm{V}_{\mathrm{A}} / \mathrm{Q}\right)$ relationships. It also incorporates recent advances in our understanding of pulmonary physiology. Afterward, this paper systematically reviews the results of clinical trials on PP from 1974 to 2014 on gas exchange, hemodynamics, VILI, associated adverse effects, and the impact of PP on other supportive therapies.

\section{Effects of PP on Chest Mechanics}

The theoretical underpinning of PP is based on a model of the chest and abdominal compartments consisting of organs with profoundly different densities separated by a thin membrane (ie, the diaphragm). ${ }^{5}$ Differences in organ densities are further magnified by disparities in their respective volumes with an abdominal compartment of $10 \mathrm{~L}$ compared with a thoracic volume of $5 \mathrm{~L} .{ }^{15}$ The abdominal 

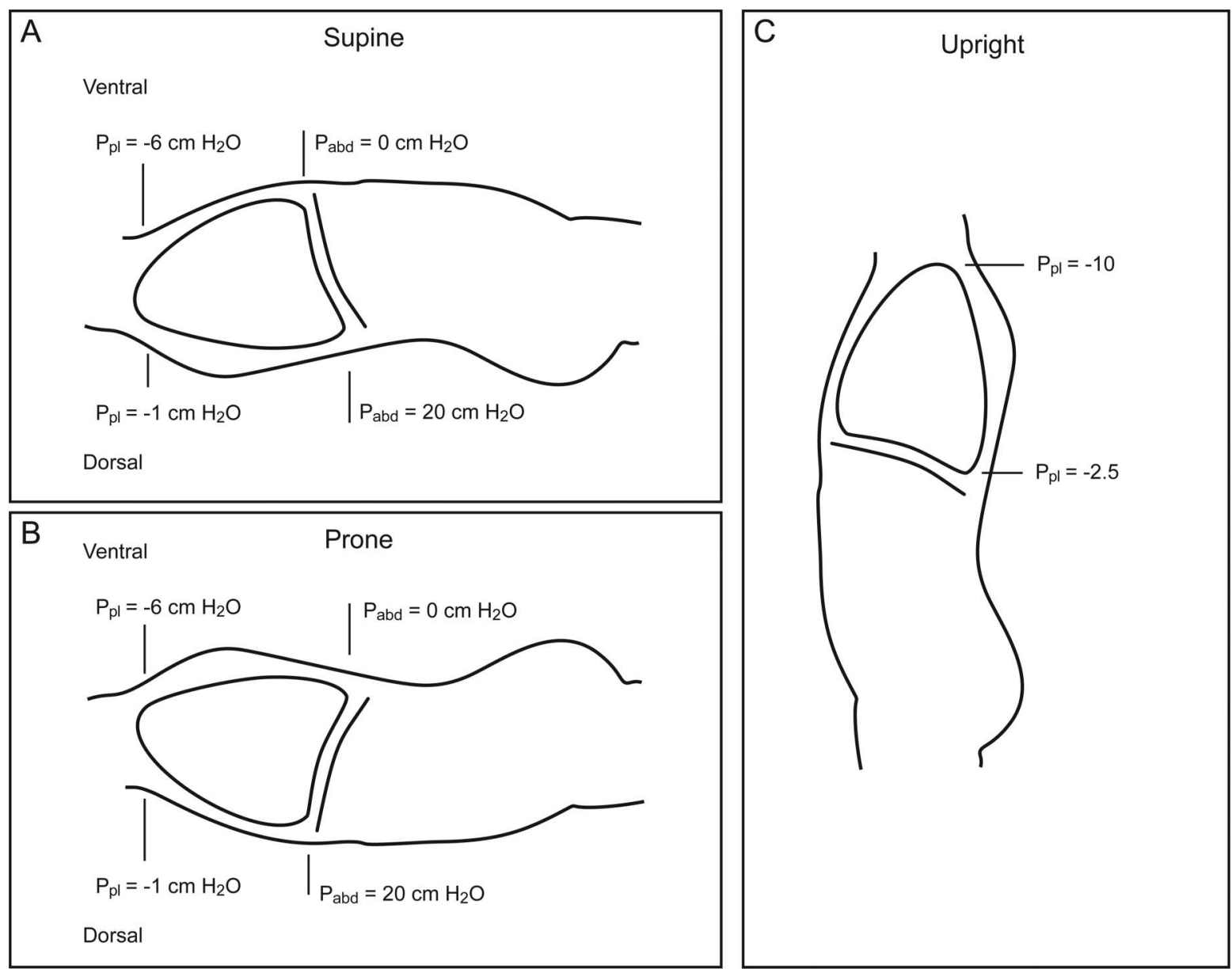

Fig. 1. Schematic representation of vertical pleural pressure (Ppl) distribution from the apex to the bases in the upright position and their respective diminishment in the recumbent supine and prone position. Numeric values for pleural pressure and hydrostatic intra-abdominal pressure (Pabd) are based on values provided by Bryan, ${ }^{5}$ whereas those in the upright position are based upon values provided by West. ${ }^{16}$ The actual values are subject to debate due to measurement techniques and the impact of lung disease. Agostoni, ${ }^{17}$ for example, estimated slightly lower ventral-dorsal values in the recumbent supine and prone position ( -4 to $0 \mathrm{~cm} \mathrm{H}_{2} \mathrm{O}$, respectively). Moreover, he cited evidence that increased lung density in respiratory disease may enhance the vertical gradient.

cavity has 2 rigid walls (anchored by the pelvis and the spine) and 2 flexible walls (its ventral surface and the diaphragm). Consequentially, both pleural pressure $\left(\mathrm{P}_{\mathrm{PL}}\right)$ and intra-abdominal pressure (IAP) change with body position and the resulting distortion of the flexible portions of the abdominal wall (Fig. 1). This in turn influences the shape and position of the diaphragm. ${ }^{18}$

In SP, the hydrostatic pressures in the abdominal compartment exceed those in the chest cavity by a factor of 5 (ie, 1.0 vs $0.2 \mathrm{~cm} \mathrm{H}_{2} \mathrm{O} / \mathrm{cm}$ height, respectively). ${ }^{4}$ Moreover, the vertical IAP gradient strongly influences the vertical $\mathrm{P}_{\mathrm{PL}}$ gradient in SP. ${ }^{19}$ Disparities in hydrostatic pressures between these compartments are magnified further with obesity and morbid obesity, wherein IAP increases from a normal of 5-7 mm $\mathrm{Hg}\left(7-9 \mathrm{~cm} \mathrm{H}_{2} \mathrm{O}\right)$ to $11-$ $16 \mathrm{~mm} \mathrm{Hg}$, respectively (14-16 $\left.\mathrm{cm} \mathrm{H}_{2} \mathrm{O}\right){ }^{20}$ ARDS associated with intra-abdominal sepsis or trauma frequently is associated with abdominal compartment syndrome, where IAP is extraordinarily elevated $(>25 \mathrm{~mm} \mathrm{Hg}$ or $34 \mathrm{~cm} \mathrm{H}_{2} \mathrm{O}$ ). ${ }^{21}$ Under all conditions, the highest IAP is measured in the dorsal regions and is transmitted to the pleural space, thus acting to compress the dorsocaudal regions of the lung.

The response of respiratory system compliance $\left(\mathrm{C}_{\mathrm{RS}}\right)$ to $\mathrm{PP}$ is variable and complex. A number of observational studies reported that $\mathrm{C}_{\mathrm{RS}}$ was unaltered or modestly decreased when turning from SP to PP in both surgical subjects $^{22,23}$ and those with ARDS. ${ }^{24-30}$ Other studies have reported improved $C_{R S}$ upon being placed in $P P,{ }^{31,32}$ after an extended period of $\mathrm{PP},{ }^{24}$ or once subjects were returned to SP. ${ }^{33}$ There is also evidence suggesting that patients with extrapulmonary sources of ARDS (ARDS ${ }_{\text {exp }}$ ) may be more likely to exhibit decreased $\mathrm{C}_{\mathrm{RS}}$ when placed in $\mathrm{PP}, 26$ possibly attributable to an accentuation of the characteristically decreased chest wall compliance $\left(\mathrm{C}_{\mathrm{CW}}\right)$ found in that condition. ${ }^{34}$ 


\section{Prone Position IN ARDS}

PP generally reduces $\mathrm{C}_{\mathrm{CW}}$, but the magnitude of impact depends in part upon the use and type of padding supports, mattress type, and baseline abdominal girth and rigidity. In contrast, change in lung compliance $\left(\mathrm{C}_{\mathrm{L}}\right)$ is dependent upon the degree of lung recruitment achieved. As an example, Lee et al ${ }^{35}$ reported that those who responded to PP with improved oxygenation also had a corresponding improvement in $\mathrm{C}_{\mathrm{L}}$ and $\mathrm{C}_{\mathrm{RS}}$ despite a significant drop in $\mathrm{C}_{\mathrm{CW}}$ (from 172 to $124 \mathrm{~mL} / \mathrm{cm} \mathrm{H}_{2} \mathrm{O}$ ), whereas nonresponders had no change in either $\mathrm{C}_{\mathrm{L}}$ or $\mathrm{C}_{\mathrm{CW}}$. Pelosi et al ${ }^{36}$ reported a similar reduction in $\mathrm{C}_{\mathrm{CW}}$ (from 205 to $147 \mathrm{~mL} / \mathrm{cm} \mathrm{H}_{2} \mathrm{O}$ ) but without improvement in $\mathrm{C}_{\mathrm{L}}$.

Blanch et $\mathrm{al}^{31}$ observed that responders to $\mathrm{PP}$ were characterized by improvements in both $\mathrm{C}_{\mathrm{RS}}$ and oxygenation suggestive of lung recruitment. Both Pelosi et $\mathrm{al}^{36}$ and Guerin et $\mathrm{al}^{37}$ assessed lung recruitment during PP by measuring changes in end-expiratory lung volume (EELV). Guerin et $\mathrm{al}^{37}$ discovered evidence of recruitment in less than half of the subjects, yet lung recruitment correlated with oxygenation. In contrast, Pelosi et $\mathrm{al}^{36}$ found no correlation between these variables. Improved oxygenation often occurs without corresponding improvements in $C_{R S}$, suggesting that improved $\mathrm{V}_{\mathrm{A}} / \mathrm{Q}$ with $\mathrm{PP}$ may be the primary mechanism in many cases.

During passive ventilation in SP, the thoracic dimensions diminish with a corresponding decrease in FRC of approximately $17 \%(0.5 \mathrm{~L})$, whereas the abdominal volume increases. ${ }^{15}$ As a result, the dorsal aspect of the diaphragm shifts cephalad, resulting in lower regional resting lung volume and $\mathrm{C}_{\mathrm{L}}$. During passive mechanical ventilation with a physiologic $\mathrm{V}_{\mathrm{T}}(5-6 \mathrm{~mL} / \mathrm{kg})$, inspired volume is preferentially distributed to the nondependent, ventral lung regions. ${ }^{4}$ For example, rib cage expansion during passive mechanical ventilation increases from 40 to $72 \%$ of total chest expansion compared with spontaneous breathing in the SP. ${ }^{38}$

PP was originally used in clinical practice for surgical procedures. It was there that problems with ventilation and hemodynamic instability (from compression of the abdominal portion of the inferior vena cava) were attributed to restricted movement of the chest and abdomen. ${ }^{39}$ The solution was to support the upper chest and pelvic region with padding to facilitate unrestricted inspiratory abdominal movement, thus improving caudal thoracic expansion and ventilation distribution. Using thoracic and abdominal supports in obese patients (mean body mass index of 35 $\mathrm{kg} / \mathrm{m}^{2}$ ) undergoing elective surgery, Pelosi et al ${ }^{22}$ reported a $20 \%$ increase in $\mathrm{C}_{\mathrm{L}}$ with a $20 \%$ decrease in $\mathrm{C}_{\mathrm{CW}}$ and a $220 \%$ increase in mean FRC. In contrast, the same investigators found that in nonobese subjects (mean body mass index of $23 \mathrm{~kg} / \mathrm{m}^{2}$ ) undergoing elective surgery, an improvement in FRC of $150 \%$ was not accompanied by an improvement in either $\mathrm{C}_{\mathrm{L}}$ or $\mathrm{C}_{\mathrm{CW}} \cdot{ }^{23}$ Both studies used a traditional $\mathrm{V}_{\mathrm{T}}$ strategy $(12$ and $10 \mathrm{~mL} / \mathrm{kg}$ ideal body weight, respectively) not typically used for patients with acute respiratory failure.

It is noteworthy that the particular method used for supporting the chest may be equally as important as body habitus. Paradoxically, chest padding can worsen compliance if the entire chest is supported lengthwise, such that the anterior abdominal wall also is compressed. ${ }^{39}$ In patients with ARDS, the need for padding support during PP is not considered an important factor. For example, Albert et $\mathrm{al}^{40}$ found that PP did not appreciably alter regional diaphragmatic movement in experimental ARDS. Chiumello et $\mathrm{al}^{41}$ found that $\mathrm{C}_{\mathrm{CW}}$ paradoxically was lower in subjects when chest and abdominal supports were used during $\mathrm{PP}\left(102 \mathrm{~mL} / \mathrm{cm} \mathrm{H}_{2} \mathrm{O}\right.$ vs $\left.158 \mathrm{~mL} / \mathrm{cm} \mathrm{H}_{2} \mathrm{O}\right)$ because of increased contact pressure at the supported sites (29 $\mathrm{cm} \mathrm{H}_{2} \mathrm{O}$ vs $17 \mathrm{~cm} \mathrm{H}_{2} \mathrm{O}$ with and without padding support, respectively). However, $\mathrm{C}_{\mathrm{L}}$ was higher when supports were used $\left(102 \mathrm{~mL} / \mathrm{cm} \mathrm{H}_{2} \mathrm{O}\right.$ vs $\left.93 \mathrm{~mL} / \mathrm{cm} \mathrm{H}_{2} \mathrm{O}\right)$. These offsetting changes in $\mathrm{C}_{\mathrm{L}}$ versus $\mathrm{C}_{\mathrm{CW}}$, with or without the use of chest and abdominal supports, had no effect on either pulmonary gas exchange or hemodynamics. However, others have cautioned that allowing for free abdominal motion may yet be an important consideration in patients with baseline hemodynamic instability, particularly if this occurs in the context of intra-abdominal hypertension. ${ }^{20}$

One of the most detailed and interesting studies on chest mechanics during PP compared the effects of PP with low-level PEEP on mechanical heterogeneity in pneumonia-induced ARDS. In this patient population, VieillardBaron et $\mathrm{al}^{42}$ reported that PP was comparable with lowlevel external PEEP in eliminating intrinsic PEEP. PP also reduced airway resistance, the expiratory time constant, and the trapped volume of a functionally noncommunicating slow compartment of the lungs. In consequence, $\mathrm{C}_{\mathrm{RS}}$ increased, and $\mathrm{P}_{\mathrm{aCO}}$ decreased. None of the subjects in this study had a history of obstructive lung disease.

\section{Ventilation/Perfusion Relationship}

The architectures of both the airways and pulmonary blood vessels share small asymmetries in their respective branching angles and diameters. These asymmetries grow in magnitude with each succeeding generation, resulting in heterogeneous distribution in ventilation and perfusion both in horizontal and vertical dimensions. ${ }^{43}$ Of particular importance is that only $1-25 \%$ of pulmonary perfusion is mediated by gravitational forces compared with the influence of vascular architecture. ${ }^{44}$ This has been referred to as the Slinky effect, ${ }^{44}$ in which the lung is analogous to a deformable spring that distorts under its own weight (eg, more spring coils gather at the base of a vertically oriented spring). Therefore, lung tissue density and, hence, pulmonary vasculature are greater in the dorsum when lying 
supine and in the bases when upright. Gravitational changes with posture also impact regional resting alveolar size because of gravity's impact on the regional trans-pulmonary pressure gradient (alveolar - pleural pressure). In SP, transpulmonary pressure decreases (ie, becomes more positive) from the ventral to dorsal lung, resulting in smaller alveolar size but also the potential for larger inspiratory volume changes during tidal ventilation. ${ }^{45}$

\section{Distribution of Ventilation in PP}

During spontaneous ventilation, diaphragmatic contraction causes a relatively greater $\mathrm{P}_{\mathrm{PL}}$ gradient that favors ventilation distribution in the dorsocaudal regions, thus maximizing $\mathrm{V}_{\mathrm{A}} / \mathrm{Q}$ matching. However, during passive mechanical ventilation (particularly with a physiologic $\mathrm{V}_{\mathrm{T}}$ ), $\mathrm{V}_{\mathrm{A}} / \mathrm{Q}$ matching becomes less effective as $\mathrm{V}_{\mathrm{T}}$ is distributed primarily to the ventral lung. ${ }^{4}$ This is explained by the rib cage component of the chest wall, which is nonhomogeneous in its displacement. The ventral chest wall has a larger freedom of movement compared with the dorsal chest wall, so that the tendency toward nonhomogeneous displacement is accentuated in SP. ${ }^{36}$ From a historical perspective, this aspect of chest mechanics also explains the initial adoption of supranormal $\mathrm{V}_{\mathrm{T}}$ during the early decades of mechanical ventilation practice. ${ }^{46-48}$

To these issues is added the superimposed compressive forces of the heart upon the lungs (particularly the left) in SP. ${ }^{49}$ Moreover, the compressive forces acting upon the lungs assume much greater importance in the presence of pulmonary or systemic inflammation as well as trauma. The superimposed pressures of the overlying edematous lung and chest wall (including the abdominal component) collapse the densely vascularized dorsocaudal lung tissue. ${ }^{50}$

The clinical relevance of managing patients in PP versus SP is based, in part, upon lung tissue distribution within the chest cavity. A substantially greater proportion of lung tissue is oriented toward the dorsum of the chest. In SP, approximately $20 \%$ of lung tissue is oriented in the ventral plane, compared with $50 \%$ in the dorsal plane (below the level of the heart). ${ }^{51}$ Although tissue mass redistributes toward the ventral portion of the chest cavity in PP, 52 relatively less tissue mass is exposed to compressive forces. Moreover, passive mechanical ventilation in PP causes a much greater dorsocaudal diaphragmatic displacement, resulting in great regional volume change (Fig. 2). ${ }^{53,54}$ Furthermore, during PP, the heart rests almost completely upon the sternum and decompresses the left lower lobe as well as a portion of the right lower lobe. ${ }^{49}$

The gravitational effects on pulmonary gas distribution are determined by spatial distribution in alveolar sizes at the commencement of inspiration that, in turn, are dictated by gravitational differences in $\mathrm{P}_{\mathrm{PL}}$ gradients (with the small-
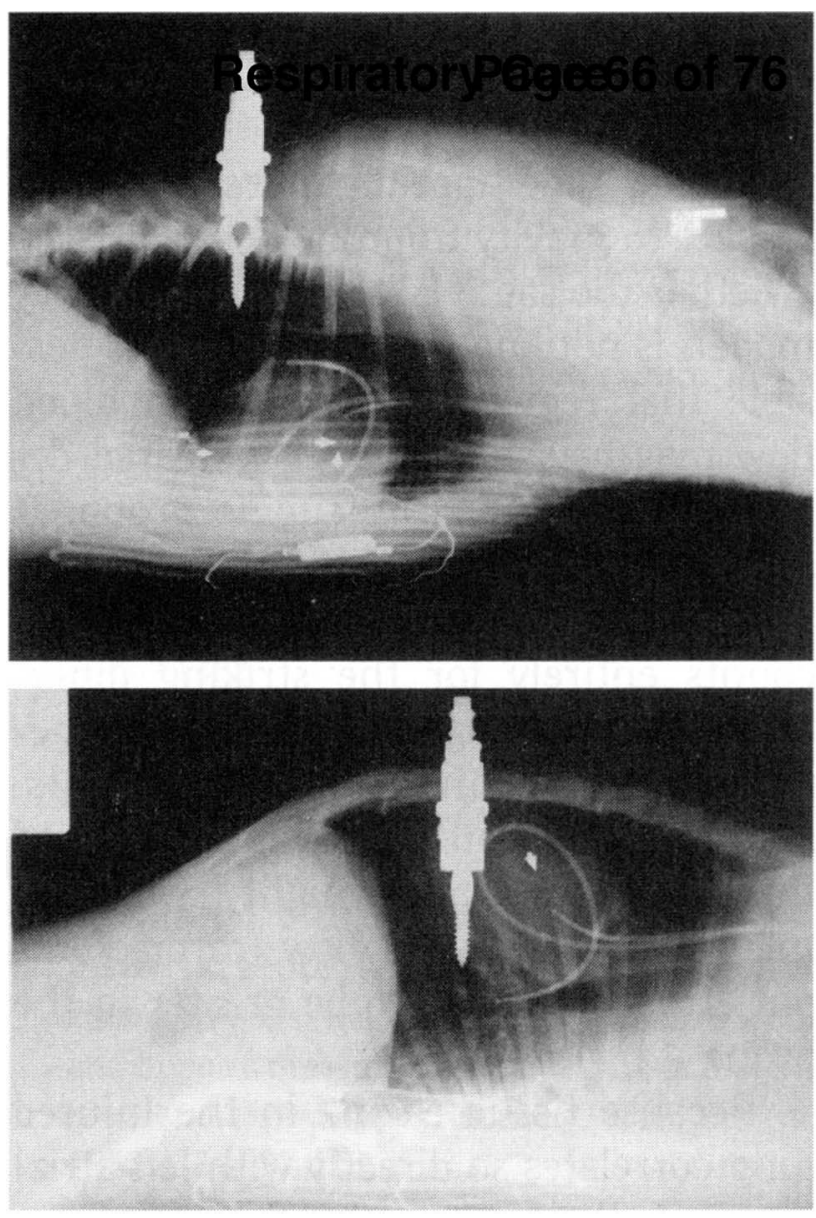

Fig. 2. Lateral chest radiograph of a dog with a fixed, external plumb bob to demonstrate marked improvement in dorsocaudal aeration in the prone position (top) versus the supine position (bottom). From Reference 53, with permission.

est fractional gas content found in the lung bases). ${ }^{43}$ In addition, when inspiration begins from residual volume compared with FRC, little volume change occurs in the dependent lung because of airway closure (this mimics the mechanical conditions present in severe ARDS). ${ }^{43}$ As the lung inflates, alveolar size distribution becomes more uniform.

Interestingly, studies of ventilation distribution in PP could not detect the effects of a gravitational $\mathrm{P}_{\mathrm{PL}}$ gradient, because alveolar tissue density was more evenly distributed compared with SP. Moreover, in normal subjects breathing either spontaneously or under anesthesia (ie, passive mechanical ventilation) in PP, regional lung volume distribution at FRC was not influenced by vertical gradients. ${ }^{55} \mathrm{~A}$ reduced, more homogeneous $\mathrm{P}_{\mathrm{PL}}$ gradient (and hence more homogeneous transpulmonary pressure gradient) with PP induces a more evenly distributed tissue stress. This is because the greater mass of dorsal lung tissue is suspended along a relatively larger horizontal dorsal chest 

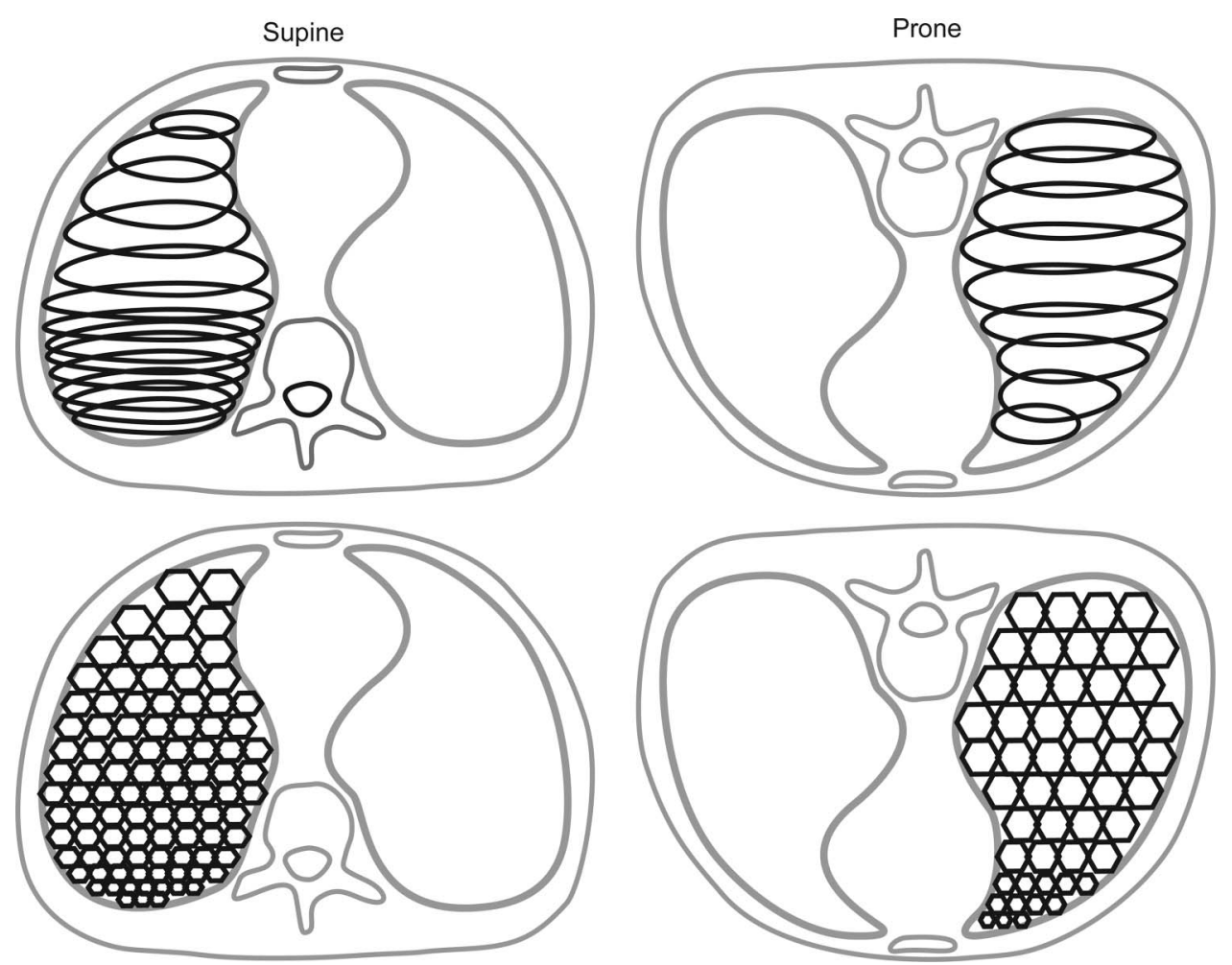

Fig. 3. Schematic representation of strain-stress distribution and its impact on alveolar size distribution between the supine and prone position. The Slinky effect of a triangular-shaped spring suspended from its apex (supine position) causes higher strain and larger variation in the distribution of alveolar sizes due to the effects of gravity and a steeper stress production during mechanical inspiration in the upper lung regions. In contrast, suspending the spring by its base across a wider surface area (prone position) produces a more even strain and more homogeneous distribution of alveolar size that lessens inhomogeneity in stress development throughout the lungs during mechanical inspiration.

wall. Specifically, in PP, the ratio of the transverse thoracic diameter to the sternovertebral height is $3: 1 .{ }^{56}$

A useful analogy likens the lung to a triangular-shaped spring alternatively suspended from its apex (analogous to $\mathrm{SP}$ ) and from its base (analogous to PP) (Fig. 3). ${ }^{57}$ The combined effects of gravity and the greater tissue mass suspended from a larger dorsal chest wall area produce more equal stress distribution throughout the lung, resulting in more uniform alveolar size (Fig. 3).

\section{Pulmonary Perfusion in PP}

In concert with these changes in lung volume distribution, several studies found that pulmonary perfusion is relatively unaffected by gravitational forces in PP and appears to be more evenly distributed despite a continued bias favoring the dorsal lung. ${ }^{52,58,59} \mathrm{In}$ part, this is because the vertical impact of gravity on pulmonary perfusion between SP and PP is estimated to account for between 4 and $7 \%$, between 4 and $13 \%$, and up to $21-41 \%$ of distribution differences, depending upon methodology. ${ }^{43,60}$

Several plausible explanations have been offered to explain the persistence of dorsal perfusion bias irrespective of body position. Pulmonary vascular endothelium production of nitric oxide is substantially greater in the dorsal versus the ventral lung. ${ }^{61}$ Also, because more lung tissue resides in the dorsal plane, there is more pulmonary vasculature available and a higher capacitance to accommodate cardiac output compared with the ventral lung, regardless of gravitational forces. Therefore, regional pulmonary vascular resistance would remain lower in the dorsal lung. Moreover, due to fractal geometry, geographic regions containing high conductance vessels tend to approximate one another, whereas a negative correlation in vascular size distribution exists between lung regions remote from one another. ${ }^{62}$ This suggests that ventral lung tissue possesses smaller caliber vasculature and hence increased resistance.

\section{Airway Closure and $\mathrm{V}_{\mathrm{A}} / \mathrm{Q}$ Matching in Experimental ARDS and PEEP During PP}

Under normal physiologic conditions in dogs, the relative effects of $\mathrm{PP}$ have been a slightly improved $\mathrm{P}_{\mathrm{aO}_{2}}$ with no change in $\mathrm{P}_{\mathrm{aCO}}$ but increased $\mathrm{V}_{\mathrm{A}} / \mathrm{Q}$ matching from 0.83 to $0.94 .{ }^{63}$ Similar findings have been reported in pigs 


\section{PRONe Position IN ARDS}

with $\mathrm{V}_{\mathrm{A}} / \mathrm{Q}$ increasing from 0.72 to 0.82 between $\mathrm{SP}$ and PP. 64

When ARDS is induced in dogs, changing from SP to PP causes major improvements in $\mathrm{P}_{\mathrm{aO}_{2}}$ attributed both to the effects of decreased intrapulmonary shunt (by approximately 50\%) and decreasing regional $\mathrm{V}_{\mathrm{A}} / \mathrm{Q}$ heterogeneity. ${ }^{40,65}$ The primary location for this effect was found in the dorsal lung. Wiener et al ${ }^{66}$ reported that the apparent ventrodorsal gravitational gradient affecting regional pulmonary perfusion in SP disappears in PP because the majority of perfusion continues to be preferentially distributed to dorsal lung regions.

Despite this fact, injury-induced extravascular lung water remains evenly distributed throughout the lungs. Pulmonary edema increases $\mathrm{P}_{\mathrm{PL}}$ in the dorsocaudal areas, causing a drop in regional transpulmonary pressure below the regional critical closing pressure in SP. ${ }^{64}$ Therefore, in PP, given the same magnitude of lung edema in the dorsocaudal lung regions, the regional $\mathrm{P}_{\mathrm{PL}}$ decreases (becomes more negative), favoring the likelihood of recruitment and participation in tidal ventilation in lung regions with a higher fraction of pulmonary perfusion.

Another important consideration is that the positional impact of $\mathrm{P}_{\mathrm{PL}}$ gradients becomes magnified during volume overload, whereby the vertical $\mathrm{P}_{\mathrm{PL}}$ gradient increases significantly in $\mathrm{SP}$ (from 0.53 to $0.71 \mathrm{~cm} \mathrm{H}_{2} \mathrm{O} / \mathrm{cm}$ ) compared with PP (from 0.17 to $0.27 \mathrm{~cm} \mathrm{H}_{2} \mathrm{O} / \mathrm{cm}$ ). The clinical implication is that aggressive fluid resuscitation (as would occur during resuscitation in sepsis or trauma-induced ARDS) has a greater impact on promoting dependent airway closure in SP than in PP. ${ }^{67}$

Severe hypervolemia causes intra-abdominal fluid collection, resulting in abdominal distention. Elevated IAP decreases $\mathrm{C}_{\mathrm{CW}}$ and markedly increases mean $\mathrm{P}_{\mathrm{PL}}$ in the dorsocaudal region from -0.2 to $+4.2 \mathrm{~cm} \mathrm{H}_{2} \mathrm{O}$ ). ${ }^{68}$ Moreover, in the presence of ARDS, elevated IAP is transmitted to the thoracic cavity, simultaneously raising pulmonary arterial pressure and compressing the thoracic veins. This potentiates pulmonary edema formation by aggravating transcapillary fluid filtration while also impairing alveolar fluid clearance ${ }^{69}$ Studying the impact of increased IAP on $\mathrm{P}_{\mathrm{PL}}$ and $\mathrm{V}_{\mathrm{A}} / \mathrm{Q}$ between SP and PP, Mure et al ${ }^{70}$ discovered that $\mathrm{PP}$ increased oxygenation primarily by decreasing $\mathrm{V}_{\mathrm{A}} / \mathrm{Q}$ heterogeneity compared with $\mathrm{SP}$, the impact being more salient in the presence of abdominal distention.

Adding to the complexity of $\mathrm{V}_{\mathrm{A}} / \mathrm{Q}$ mismatching in ARDS is emerging evidence that the intensity of hypoxic pulmonary vasoconstriction is heterogeneous in its distribution. ${ }^{71-73}$ In brief, hypoxic pulmonary vasoconstriction varies by lung regions. More intense vasoconstriction occurs in the ventrocranial lung regions, whereas the weakest response (and therefore the largest relative increase in pulmonary perfusion) occurs in the dorsocaudal regions. There is evidence of intrinsically higher endothelial expression of nitric oxide in these regions, which may modulate the response to endothelin-1 (a potent vasoconstrictor released during hypoxia). There also may be uneven distribution of vascular smooth muscle arrangements and densities between lung regions that modify the compensatory response to hypoxia. ${ }^{72}$

Moreover, when regional hypoxia becomes severe (ie, alveolar $\mathrm{P}_{\mathrm{O}_{2}}<50 \mathrm{~mm} \mathrm{Hg}$ ), hypoxic pulmonary vasoconstriction fails as a compensatory mechanism. ${ }^{73}$ The potential clinical relevance is that PP would compensate for the weaker vasoconstrictor response by facilitating alveolar recruitment and increasing alveolar ventilation in the dorsacaudal lung regions, thereby eliminating, or at least ameliorating, the stimulus for pulmonary vasoconstriction.

Finally, the effects of PEEP on pulmonary perfusion differ considerably between SP and PP. Under normal physiologic conditions, the application of high-level PEEP $\left(20 \mathrm{~cm} \mathrm{H}_{2} \mathrm{O}\right.$ ) in $\mathrm{SP}$ exaggerates the gravitational forces influencing lung perfusion by redistributing pulmonary perfusion away from the upper and middle zones to dorsal lung regions. This creates areas of very high $\mathrm{V}_{\mathrm{A}} / \mathrm{Q}$ and increased $\mathrm{V}_{\mathrm{D}} / \mathrm{V}_{\mathrm{T}}$, partly caused by deterioration in cardiac output. $^{74}$ To avoid this confounding effect, others have applied low-level PEEP $\left(5 \mathrm{~cm} \mathrm{H}_{2} \mathrm{O}\right)$ in sheep with normal lungs and found that pulmonary perfusion heterogeneity increased only modestly (15\%) in SP.75

In response to both moderate and high-level PEEP, markedly different patterns of pulmonary perfusion distribution (both in the vertical and horizontal planes) were found between SP and PP. In PP at 0 and $10 \mathrm{~cm} \mathrm{H}_{2} \mathrm{O}$ PEEP, perfusion to the nondependent (dorsal) lung was unaltered, and it actually increased at a PEEP of $20 \mathrm{~cm} \mathrm{H}_{2} \mathrm{O} .{ }^{76}$ Less perfusion heterogeneity within horizontal planes also was found in PP at all levels of PEEP. Decreased heterogeneity in pulmonary perfusion distribution with PEEP during PP has been reported by others. ${ }^{77}$ Moreover, whereas the paradigm of zonal (gravitational) effects on pulmonary perfusion distribution explained the results found in response to PEEP during SP, this effect was absent during PP. This finding again reinforces the idea that anatomic and/or physiologic differences in the pulmonary vasculature primarily determine pulmonary perfusion distribution in PP.

More homogeneous transpulmonary pressure distribution in PP probably results in more uniform lung expansion when PEEP is applied and therefore may cause negligible redistribution of pulmonary perfusion. ${ }^{75}$ Such speculation was supported by a study on ventilation distribution between SP and PP with the application of PEEP. Greater heterogeneities in ventilation distribution in total as well as within isogravitational planes were increased in $\mathrm{SP}$ at both 0 and $10 \mathrm{~cm} \mathrm{H}_{2} \mathrm{O}$ PEEP. In contrast, gravitational heterogeneity was less in PP, and the application of $10 \mathrm{~cm} \mathrm{H}_{2} \mathrm{O}$ PEEP resulted in even more uniform ventilation distribution. ${ }^{78}$ 
In another experimental ARDS study, application of moderate-level PEEP $\left(10 \mathrm{~cm} \mathrm{H}_{2} \mathrm{O}\right)$ resulted in significant alveolar recruitment in both SP and PP. ${ }^{79}$ PEEP caused a redistribution of both ventilation and perfusion toward the dependent lung in both SP and PP. However in SP, PEEPinduced alveolar recruitment occurred only in the dorsal lung, whereas applying PEEP during PP affected alveolar recruitment diffusely down the dorsoventral aspects of the lung.

\section{Effects of PP on Oxygenation in ARDS}

Since 1974, at least 40 observational studies have reported that most subjects with ARDS placed in PP exhibit mild to dramatic improvements in oxygenation. 2,3,24,26,27-33,35-37,42,56,80-105 Improvements occur regardless of lung injury categorization (pulmonary ARDS $\left[\mathrm{ARDS}_{\mathrm{p}}\right.$ ] or $\left.\mathrm{ARDS}_{\text {exp }}\right),{ }^{26,56,84,86,87,91,102}$ specific etiology (pneumonia, ${ }^{42}$ aspiration, ${ }^{90}$ following extensive surgery, ${ }^{29}$ trauma, ${ }^{33}$ acute brain injury, ${ }^{100,101}$ presence of morbid obesity, ${ }^{105}$ or severe burns and inhalational injuries ${ }^{94}$ ), or severity of lung injury. ${ }^{33,36,85}$ Significant improvement in oxygenation also has been reported in pediatric ARDS, ${ }^{106-109}$ neonates with or without respiratory distress syndrome, ${ }^{110-112}$ subjects with other causes of hypoxemia, 87 and cardiothoracic ${ }^{113,114}$ and other surgical subjects ${ }^{23}$ as well as in those with hydrostatic pulmonary edema ${ }^{97}$ and COPD. ${ }^{115}$

The most detailed clinical study of PP on gas exchange in ARDS, either from direct (pulmonary) injury (ARDS $\mathrm{p}_{\mathrm{p}}$ ) or $\mathrm{ARDS}_{\text {exp }}$ from indirect blood-borne sources, reported that the predominant defect in SP was uneven alveolar $\mathrm{V}_{\mathrm{A}} / \mathrm{Q}$ matching. ${ }^{56}$ When these subjects were placed in PP, $\mathrm{V}_{\mathrm{A}} / \mathrm{Q}$ mismatching decreased from 44 to $34 \%$. These improvements, however, were essentially lost upon returning to SP.

PP may be most effective in improving oxygenation when initiated early (eg, $\leq 3 \mathrm{~d}$ ) during the exudative phase, when congestive and compressive atelectasis are predominant features, ${ }^{29,31}$ as opposed to the intermediate phase of ARDS (eg, $>1$ week), when fibrosis and Type II cell hyperplasia are more prevalent. ${ }^{116}$ For example, initiating PP within $3 \mathrm{~d}$ of ARDS onset resulted in substantial improvement in $\mathrm{P}_{\mathrm{OO}_{2}} / \mathrm{F}_{\mathrm{IO}_{2}}$ compared with initiation at approximately 5 d. ${ }^{97}$ The same study found that subjects with hydrostatic pulmonary edema had a similar oxygenation response to early ARDS, whereas those with pulmonary fibrosis (similar to the intermediate phase of ARDS) showed no improvement. Nonetheless, several studies have reported significant improvements in oxygenation even when PP was initiated at a mean of 6-11 d after ARDS onset. $^{24,27,30,33,82,86,87}$

\section{Prevalence of Positive Oxygenation Response}

The proportion of subjects whose oxygenation improves with PP varies according to arbitrary study criteria, including cut-off values deemed relevant for oxygenation improvement as well as the time point chosen for assessing the response. It is also determined by the number of subjects sampled. Among the 31 observational studies reviewed, between 54 and 100\% exhibited improved oxygenation. Twenty percent of studies reported a positive oxygenation response in $<70 \%$ of subjects, $35,56,80,81,85,94$ whereas $47 \%$ reported a positive response in $70-85 \%$ of subjects, ${ }^{3,30,32,37,82,84,86,92,97,102,105,108,115}$ and $33 \%$ of studies found improved oxygenation in approximately $\geq 90 \%$ of subjects. ${ }^{24,27-29,33,83,87-89,99,100}$ Most studies have used cut-off values of $10-20 \mathrm{~mm} \mathrm{Hg}$ improvement in either $\mathrm{P}_{\mathrm{aO}_{2}}$ or $\mathrm{P}_{\mathrm{aO}_{2}} / \mathrm{F}_{\mathrm{IO}_{2}}{ }^{32,36,56,85,95,10}$ or a $10-20 \%$ increase in $\mathrm{P}_{\mathrm{aO}_{2}} / \mathrm{F}_{\mathrm{IO}_{2}}$ as clinically important. ${ }^{31,83,86,91,97,105}$

\section{Magnitude of Oxygenation Response}

The actual mean and ranges of oxygenation improvement with PP have been more impressive than the minimum cut-off values used to assess efficacy. In observational studies that reported $\mathrm{P}_{\mathrm{aO}_{2}}$, the average increase ranged from 23 to $78 \mathrm{~mm} \mathrm{Hg}$, or an improvement of $34-62 \%, 2,3,24,56,80,81,101$ Of the observational studies reviewed that measured $\mathrm{P}_{\mathrm{aO}_{2}} / \mathrm{F}_{\mathrm{IO}_{2}}$, the mean increase ranged from 21 to $161 \mathrm{~mm} \mathrm{Hg}$ (19-168\% improvement). ${ }^{26,27,29-33,36,37,82,84-97,42,103,105,108}$ The magnitude of improvement in $\mathrm{P}_{\mathrm{aO}} / \mathrm{F}_{\mathrm{IO}_{2}}$ among morbidly obese subjects versus nonobese subjects with ARDS was found to be significantly greater $(104 \mathrm{~mm} \mathrm{Hg}$ vs $61 \mathrm{~mm} \mathrm{Hg}$, respectively, $P=.04$ ) and was also observed in a larger proportion of subjects (77\% vs $50 \%$, respectively, $P=.044$ ). ${ }^{105}$

Similar positive responses also have been reported in subjects without ARDS, where the mean $\mathrm{P}_{\mathrm{aO}_{2}} / \mathrm{F}_{\mathrm{IO}_{2}}$ increase was from 39-192 mm $\mathrm{Hg}$ (24-267\% improvement).23,87,97,113,115 Among the few interventional PP studies that presented tabular data, similar improvements in $\mathrm{P}_{\mathrm{aO}_{2}}(28-37 \mathrm{~mm} \mathrm{Hg})$ and $\mathrm{P}_{\mathrm{aO}_{2}} / \mathrm{F}_{\mathrm{IO}_{2}}(60-75 \mathrm{~mm} \mathrm{Hg})$ were documented. ${ }^{117-119}$ Only the pediatric study by Curley et al ${ }^{120}$ reported modest improvements in mean $\mathrm{P}_{\mathrm{aO}_{2}} / \mathrm{F}_{\mathrm{IO}_{2}}$ of $30 \mathrm{~mm} \mathrm{Hg}$ during early ARDS.

\section{Temporal and Etiological Aspects of Oxygenation Response}

The time required for oxygenation to improve during PP is highly variable. Regardless of ARDS classification, the typical response is rapid initial improvement in oxygenation (ie, $<30 \mathrm{~min}$ ), followed by a more gradual increase over an extended, variable time frame. In both $\mathrm{ARDS}_{\mathrm{p}}$ and ARDS $_{\text {exp }}$, Papazian et al ${ }^{86}$ reported that $73 \%$ of responders 
to PP exhibited a fast $(1 \mathrm{~h})$ improvement in $\mathrm{P}_{\mathrm{aO}_{2}} / \mathrm{F}_{\mathrm{IO}_{2}}$, whereas $27 \%$ were characterized as slow responders, requiring $6 \mathrm{~h}$. In $\mathrm{ARDS}_{\mathrm{p}}$, Langer et al ${ }^{80}$ reported that $\mathrm{P}_{\mathrm{aO}}$ increased from 70 to $90 \mathrm{~mm} \mathrm{Hg}$ at $30 \mathrm{~min}$ and reached $112 \mathrm{~mm} \mathrm{Hg}$ at $2 \mathrm{~h}$. Pappert et al ${ }^{56}$ reported similar results, with $\mathrm{P}_{\mathrm{aO}_{2}} / \mathrm{F}_{\mathrm{IO}}$ improving from 98 to $136 \mathrm{~mm} \mathrm{Hg}$ at $30 \mathrm{~min}$ to $146 \mathrm{~mm} \mathrm{Hg}$ at $2 \mathrm{~h}$ among subjects with $\mathrm{ARDS}_{\mathrm{p}}$ or ARDS $_{\text {exp }}$

Steady oxygenation improvements over a prolonged time course have been a consistent feature of many studies. In trauma-associated ARDS, Fridrich et $\mathrm{al}^{24}$ found an immediate increase in $\mathrm{P}_{\mathrm{aO}_{2}} / \mathrm{F}_{\mathrm{IO}_{2}}$ with continued improvement over $20 \mathrm{~h}$. Likewise, in ARDS associated with severe burns, Hale et al ${ }^{94}$ observed that mean $\mathrm{P}_{\mathrm{aO}_{2}} / \mathrm{F}_{\mathrm{IO}_{2}}$ increased almost immediately after placement in PP (from 87 to $133 \mathrm{~mm} \mathrm{Hg}$ ) and improved steadily until reaching a peak of $236 \mathrm{~mm} \mathrm{Hg}$ at $36 \mathrm{~h}$. Reutershan et al ${ }^{92}$ described both subjects whose oxygenation plateaued early ( $2-4 \mathrm{~h})$ and those with continual improvement over $8 \mathrm{~h}$. Stocker et $\mathrm{al}^{27}$ observed subjects who required up to $24 \mathrm{~h}$ before oxygenation improved.

Patients with $\mathrm{ARDS}_{\mathrm{p}}$ and $\mathrm{ARDS}_{\text {exp }}$ may respond differently in terms of intensity and time course. Lim et $\mathrm{al}^{26}$ observed that subjects with $\mathrm{ARDS}_{\mathrm{p}}$ required $2 \mathrm{~h}$ of PP to substantially improve $\mathrm{P}_{\mathrm{aO}} / \mathrm{F}_{\mathrm{IO}_{2}}(37 \%)$, whereas those with ARDS $_{\text {exp }}$ had significant improvement at $30 \mathrm{~min}(45 \%)$ but showed no further improvement at $2 \mathrm{~h}(46 \%)$. In subjects with ARDS $_{\mathrm{p}}$, Jolliet et al ${ }^{85}$ found no improvement in $\mathrm{P}_{\mathrm{aO}_{2}} / \mathrm{F}_{\mathrm{IO}_{2}}$ beyond $30 \mathrm{~min}$, whereas L'Her et al ${ }^{89}$ reported a progressive increase in $\mathrm{P}_{\mathrm{aO}_{2}} / \mathrm{F}_{\mathrm{IO}_{2}}$ at 1,4 , and $12 \mathrm{~h}$. Charron et al ${ }^{93}$ reported that $>15 \mathrm{~h}$ in $\mathrm{PP}$ was required to achieve a significant increase in $\mathrm{P}_{\mathrm{aO}_{2}} / \mathrm{F}_{\mathrm{IO}_{2}}$ in subjects with severe ARDS $_{\mathrm{p}}$. Subjects with either ARDS or ARDS exp $_{\text {studied }}$ by McAuley et al ${ }^{88}$ had progressive improvements in $\mathrm{P}_{\mathrm{aO}_{2}}$ $/ \mathrm{F}_{\mathrm{IO}_{2}}$ over $20 \mathrm{~h}$. More importantly, an increasing number of subjects became responders during this time period from $73 \%(1 \mathrm{~h})$ to $100 \%(20 \mathrm{~h})$.

Two studies have explored the impact of extraordinarily prolonged PP sessions on oxygenation ( $\geq 48 \mathrm{~h}$ ). Nakos et al ${ }^{197}$ found that $\mathrm{P}_{\mathrm{aO}} / \mathrm{F}_{\mathrm{IO}_{2}}$ continuously improved from 130 (30 min) to $218 \mathrm{~mm} \mathrm{Hg}$ at $48 \mathrm{~h}$. Moreover, they observed that late responders tended to be either subjects with $\mathrm{ARDS}_{\mathrm{p}}$ or those in the late phase of the syndrome. Finally, Romero et al ${ }^{98}$ maintained PP for $55 \mathrm{~h}$ and also reported similar, continued improvement throughout in $\mathrm{P}_{\mathrm{aO}_{2}} / \mathrm{F}_{\mathrm{IO}_{2}}(92 \mathrm{~mm} \mathrm{Hg}$ vs $227 \mathrm{~mm} \mathrm{Hg}$ ) in subjects with $\operatorname{ARDS}_{\mathrm{p}}$.

Other temporal aspects of oxygenation in PP are reproducible improvement upon repeated $\mathrm{PP}$, progressive and sustained improvement over time (particularly upon return to SP), and whether initial failure to improve gas exchange represents definitive therapeutic failure. There is evidence suggesting that in both patients with $\mathrm{ARDS}_{\mathrm{p}}$ and those with $\mathrm{ARDS}_{\text {exp }}$, initial nonresponders to PP may become responders on subsequent attempts. ${ }^{3,33}$ In subjects with ARDS related to trauma and high-risk surgery, Johannigman et al ${ }^{29}$ described a consistently high rate (86\%) of significantly improved oxygenation over $6 \mathrm{~d}$ of PP therapy. Likewise, Fridrich et al ${ }^{24}$ reported that approximately half of their subjects with trauma-related ARDS were slow responders who required $>1$ week of extended PP sessions $(\sim 20 \mathrm{~h})$. However, on average, PP was initiated in these subjects at approximately 1 week of mechanical ventilation. Easby et $\mathrm{al}^{90}$ observed a trend toward ongoing improvements in oxygenation with repeated PP sessions in subjects with $\mathrm{ARDS}_{\mathrm{p}}$. Stocker et $\mathrm{al}^{27}$ found that oxygenation improved progressively until a plateau was reached after the third trial. Similarly, Charron et al ${ }^{121}$ reported that $84 \%$ of subjects required $\geq 3$ PP sessions of 18 -h duration to stabilize oxygenation.

Many observational studies reported sustained improvements in oxygenation once subjects are returned to SP. $2,24,32,35,36,80,86,87,89,94,98,113$ This has been referred to as "tissue memory," but more precisely the mechanism is tissue hysteresis as described by pressure-volume curve characteristics of the chest. ${ }^{122}$ However, many of these observations were time-limited (eg, 1-2 $\mathrm{h}$ after return to supine position), so that progressive loss of FRC and oxygenation, particularly in patients with anasarca and/or highly elevated IAP, is likely to occur over a more extended time period.

\section{Alveolar Ventilation and Recruitment During PP in ARDS}

The effects of PP on $\mathrm{P}_{\mathrm{aCO}}$ have been inconsistent in clinical studies. The majority of observational studies reported no improvement in $\mathrm{P}_{\mathrm{aCO}},{ }^{23,24,27,29,31,35,56,80-82,85,91,103}$ and sometimes increased $\mathrm{P}_{\mathrm{aCO}}$ during PP.,56 This finding is puzzling because gas exchange improvements with $\mathrm{PP}$, through better $\mathrm{V}_{\mathrm{A}} / \mathrm{Q}$ matching and reduced intrapulmonary shunt from recruitment, are both mechanisms associated with improved physiologic dead-space fraction $\left(\mathrm{V}_{\mathrm{D}} / \mathrm{V}_{\mathrm{T}}\right)$ in ARDS. ${ }^{123}$ In some studies, $\mathrm{PP}$ increased $\mathrm{P}_{\mathrm{aCO}}$ because decreased $\mathrm{C}_{\mathrm{CW}}$ reduced $\mathrm{V}_{\mathrm{T}}$ and minute ventilation in subjects managed with pressure control ventilation. ${ }^{56}$

Nevertheless, a substantial number of studies have reported decreased $\mathrm{P}_{\mathrm{aCO}}$ with PP. ${ }^{28,93,98,42,104,115,124-126}$ Romero et $\mathrm{al}^{98}$ found an initial decrement in $\mathrm{P}_{\mathrm{aCO}_{2}}$ after $30 \mathrm{~min}$ in PP (from 54 to $45 \mathrm{~mm} \mathrm{Hg}$ ) that continued to improve over $55 \mathrm{~h}(39 \mathrm{~mm} \mathrm{Hg})$. Protti et al ${ }^{104}$ studied subjects ventilated with either volume or pressure control ventilation. They attributed decreased $\mathrm{P}_{\mathrm{aCO}}$ either to improved $\mathrm{C}_{\mathrm{L}}$ from alveolar recruitment (which increased $\mathrm{V}_{\mathrm{T}}$ delivery during pressure control ventilation) or to an overall reduction in alveolar dead-space during volume control ventilation. Another mechanism that may sometimes explain drastic reductions in $\mathrm{P}_{\mathrm{aCO}}$ with $\mathrm{PP}$ is the reduction in pulmonary hypertension and associated intracardiac shunt- 
ing in patients with ARDS and cor pulmonale (see effects of PP on right heart function). ${ }^{125}$

Recently, several investigators $93,95,104,126$ have classified subjects treated with PP as either $\mathrm{P}_{\mathrm{aO}_{2}}$ or $\mathrm{P}_{\mathrm{aCO}}$ responders. Protti et al ${ }^{104}$ observed that improved $\mathrm{P}_{\mathrm{aCO}_{2}}$ rather than $\mathrm{P}_{\mathrm{aO}_{2}}$ was associated with the magnitude of lung injury and recruitment potential. What distinguished $\mathrm{P}_{\mathrm{aCO}}$ responders from nonresponders was the amount of non-aerated tissue. Indirectly, $\mathrm{P}_{\mathrm{aCO}_{2}}$ response signified the magnitude of pulmonary edema and compressive forces acting on the dorsal lung as well as the recruitment potential of PP. Charron et al ${ }^{93}$ found that subjects categorized as $\mathrm{P}_{\mathrm{aCO}_{2}}$ responders after $15 \mathrm{~h}$ of $\mathrm{PP}$ (decreased $\mathrm{P}_{\mathrm{aCO}_{2}}>2 \mathrm{~mm} \mathrm{Hg}$ ) had decreased alveolar dead-space and increased $\mathrm{C}_{\mathrm{RS}}$ as well as increased $\mathrm{P}_{\mathrm{aO}_{2}} / \mathrm{F}_{\mathrm{IO}_{2}}$.

In contrast, classification according to $\mathrm{P}_{\mathrm{aO}_{2}}$ response was not associated with changes in either $\mathrm{CO}_{2}$-related variables or $\mathrm{C}_{\mathrm{RS}}$. The maximum decrease in $\mathrm{P}_{\mathrm{aCO}}$ occurred after $9 \mathrm{~h}$ in PP compared with $15 \mathrm{~h}$ for maximum improvement in $\mathrm{P}_{\mathrm{aO}_{2}} / \mathrm{F}_{\mathrm{IO}_{2}}$. Lee et al, ${ }^{95}$ however, reported that only $\mathrm{P}_{\mathrm{aO}_{2}}$ response to PP was associated with 28-d mortality in subjects with severe ARDS. Although a similar trend was observed between $\mathrm{P}_{\mathrm{aCO}}$ responders versus nonresponders, it was not statistically significant.

In a study examining the effects of PP following a recruitment maneuver between subjects with diffuse versus lobar ARDS, Galiatsou et al. ${ }^{124}$ found that PP caused a significant decrease in $\mathrm{P}_{\mathrm{aCO}_{2}}$ only in those with lobar ARDS, and, consistent with the findings of Charron et al, ${ }^{93}$ the positive $\mathrm{P}_{\mathrm{aCO}_{2}}$ response also was associated with the largest improvement in $\mathrm{P}_{\mathrm{aO}_{2}} / \mathrm{F}_{\mathrm{IO}_{2}}$ and $\mathrm{C}_{\mathrm{RS}}$. Using $\mathrm{CT}$ imaging, Galiatsou et al. ${ }^{124}$ found that PP increased recruitment of the non-aerated dorsal lung tissue while decreasing overinflated lung tissue in the ventral and middle lungs. ${ }^{124}$ In subjects with diffuse ARDS, PP decreased the amount of non-aerated lung but did not reduce the amount of overinflated lung. This suggests that a positive $\mathrm{P}_{\mathrm{aCO}}$ response to PP may signify both the magnitude of non-aerated lung tissue and its recruitability but also more even gas distribution and reduced overinflation.

PP also may decrease $\mathrm{P}_{\mathrm{aCO}_{2}}$ by reducing heterogeneous lung emptying and intrinsic PEEP. Vieillard-Baron et al ${ }^{42}$ discovered that applying low-level PEEP $\left(6 \mathrm{~cm} \mathrm{H}_{2} \mathrm{O}\right)$ and $\mathrm{PP}$ in severe ARDS decreased mean airway resistance by $24 \%$, reduced the expiratory time constant by $23 \%$, increased $\mathrm{C}_{\mathrm{RS}}$ by $22 \%$, and decreased mean $\mathrm{P}_{\mathrm{aCO}}$ by $5 \mathrm{~mm} \mathrm{Hg}$. These changes coincided with a 55\% reduction in the "slow compartment" representing gas trapping in areas of the lung that "poorly communicate" during tidal ventilation and probably signify areas that are overinflated and therefore at risk of stretch-related lung injury.

Finally, a post hoc analysis ${ }^{126}$ of 225 subjects enrolled in a multi-center RCT of PP reported that $\mathrm{P}_{\mathrm{aCO}}$ responders $\left(\mathrm{P}_{\mathrm{aCO}_{2}}\right.$ decrease $\left.\geq 1 \mathrm{~mm} \mathrm{Hg}\right)$ had improved 28-d survival, whereas a positive $\mathrm{P}_{\mathrm{aO}}$ response $\left(\mathrm{P}_{\mathrm{aO}_{2}} / \mathrm{F}_{\mathrm{IO}_{2}}\right.$ increase $\geq 20 \mathrm{~mm} \mathrm{Hg}$ ) was not associated with outcome. $\mathrm{P}_{\mathrm{aCO}_{2}}$ responders had a mean decrease of $6 \mathrm{~mm} \mathrm{Hg}$ and a mortality of $35 \%$, whereas $\mathrm{P}_{\mathrm{aCO}}$ nonresponders had a mean increase of $6 \mathrm{~mm} \mathrm{Hg}$ and a mortality of $52 \%$. Moreover, when all subjects randomized to PP were examined, there was no net change in mean $\mathrm{P}_{\mathrm{aCO}_{2}}(0.4 \pm 8.2 \mathrm{~mm} \mathrm{Hg})$ despite a drastic improvement in $\mathrm{P}_{\mathrm{aO}_{2}} / \mathrm{F}_{\mathrm{IO}_{2}}$ $(70 \pm 70 \mathrm{~mm} \mathrm{Hg})$.

This finding helps to explain the sample-level lack of $\mathrm{P}_{\mathrm{aCO}_{2}}$ response in small observational studies of PP. A relatively equal distribution between $\mathrm{P}_{\mathrm{aCO}_{2}}$ responders and nonresponders would negate cohort-level changes in $\mathrm{P}_{\mathrm{aCO}_{2}}$ despite an overall improvement in oxygenation. The authors attributed the improved $\mathrm{P}_{\mathrm{aCO}_{2}}$ to increased recruitment of non-aerated lung that exceeded the negative effects of decreased $\mathrm{C}_{\mathrm{CW}}$. This suggests that $\mathrm{CO}_{2}$ (which is approximately 20 times more diffusible than $\mathrm{O}_{2}$ across tissues) is more perfusion-sensitive and therefore a better marker of lung recruitment in ARDS ${ }^{123}$ and thus may indirectly signify a reduced risk for VILI.

In summary, several mechanisms are probably responsible for the improved gas exchange when patients with ARDS are placed in PP. These include changes in diaphragm position and/or tidal diaphragmatic motion, less cardiac-induced compression of the lungs, and increased trans-pulmonary pressure in the dorsal caudal lung facilitating alveolar recruitment (Fig. 4). The more homogeneous distribution of trans-pulmonary pressure results in more uniformity of alveolar size and regional end-expiratory lung volume. As a consequence, both regional compliance and therefore $\mathrm{V}_{\mathrm{T}}$ distribution should also become more uniform. Furthermore, these effects on lung volume also reduce pulmonary vascular resistance heterogeneity by reducing local hypoxic pulmonary vasoconstriction and increasing overall $\mathrm{V}_{\mathrm{A}} / \mathrm{Q}$ matching.

\section{Effects of PP on Airway Secretion Clearance and Ventilator-Associated Pneumonia}

PP probably improves gas exchange by enhancing secretion drainage. Most patients with ARDS respond to PP with increased oxygenation without noticeable secretion drainage. ${ }^{127}$ However, several studies ${ }^{2,80,82,87,114,115}$ reported copious secretion mobilization in some subjects upon turning to PP that may improve oxygenation and alveolar ventilation as well as potentially reducing the incidence of ventilator-associated pneumonia (VAP).

It has been speculated PP might reduce the incidence of VAP by several mechanisms. Prolonged immobilization in the supine position has long been associated with "hypostatic pneumonia" arising from atelectasis and retained secretions, primarily in posterior and superior segments of the lower lobes. ${ }^{128}$ This is because the trachea and main 

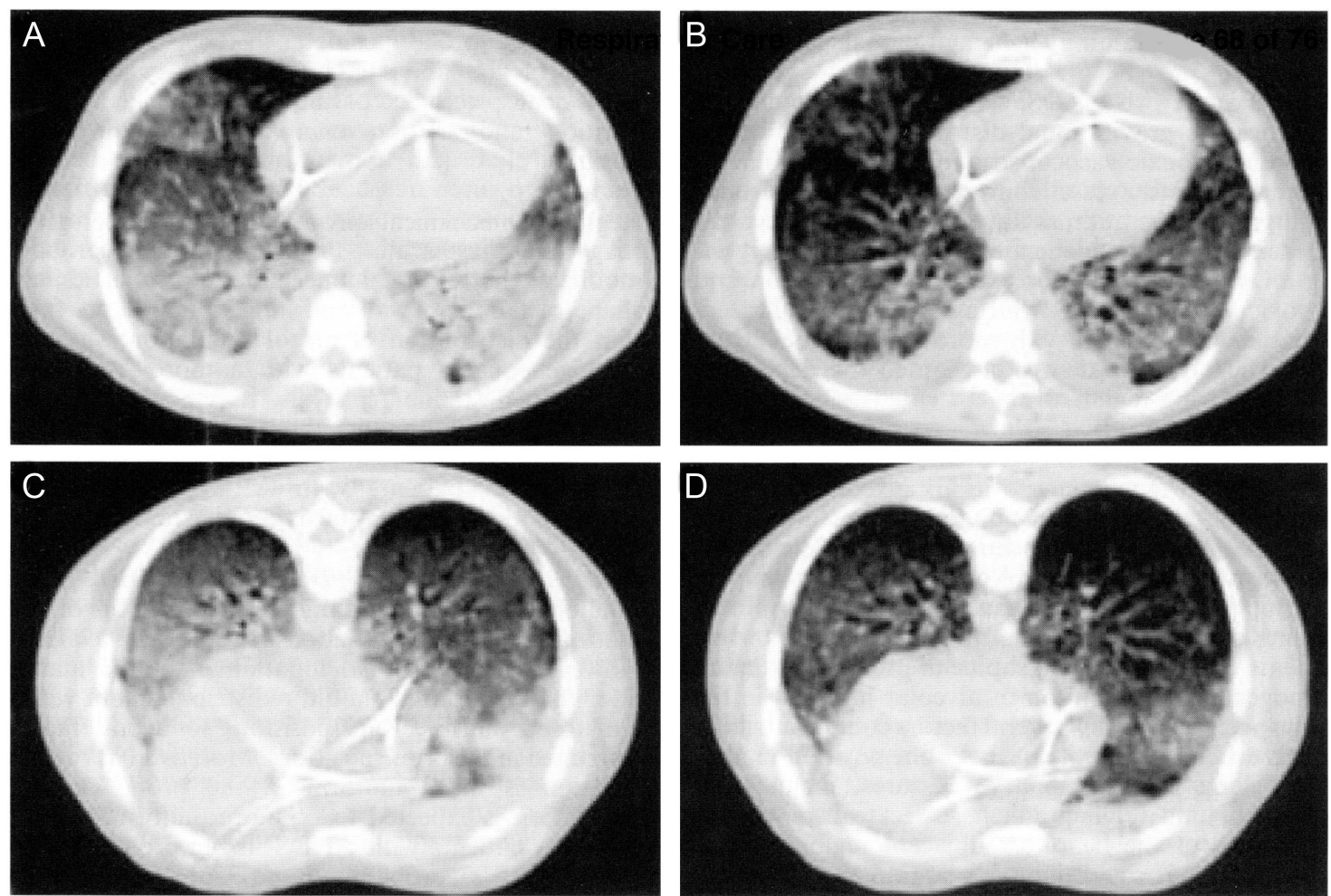

Fig. 4. Differences in the distribution of lung densities in a patient with ARDS on a computed tomography scan between supine position (top) and prone position (bottom). A: Image taken at end expiration in the supine position. B: Image taken at end inspiration in the supine position. Images $\mathrm{C}$ and $\mathrm{D}$ were taken from the same lung volumes in the prone position. Note the improved aeration in the dorsal lungs both at end expiration and end inspiration in the prone position compared with the supine position. From Reference 116, with permission.

bronchi are oriented toward the dorsum, favoring gravitational flow and subsequent pooling of secretions deeper into the lungs. ${ }^{129}$ Therefore, PP would promote forward drainage toward the central airways to facilitate secretion clearance. PP is thought to limit both gastroesophageal reflux and the pooling of oropharyngeal secretions above the endotracheal tube cuff, thus limiting microaspiration of infected secretions into the lower respiratory tract. ${ }^{129}$ However, other studies have found that PP is associated with a higher incidence of increased gastric residual volumes, which is a risk factor for aspiration pneumonia. ${ }^{130}$

Several RCTs have examined the impact of PP on the incidence of VAP as a secondary outcome with mixed results. In the only RCT in which the incidence of VAP was the primary outcome, acute brain-injured subjects who received intermittent PP $(4 \mathrm{~h} / \mathrm{d})$ showed a strong trend toward a lower incidence of VAP compared with SP with head of bed elevation maintained at 20 degrees, $(20 \%$ vs $38 \%$, respectively $P=.14) .{ }^{131}$ In trauma-associated ARDS, Voggenreiter et al ${ }^{132}$ found a significantly lower prevalence of VAP compared with SP (62\% vs $89 \%$ respectively, $P<.05)$. Among subjects with various causes of hypoxemic acute respiratory failure, Guerin et al ${ }^{118}$ also found a significant reduction in both the prevalence $(20.6 \%$ vs $24.1 \%)$ and incidence density (1.66/100 d vs $2.14 / 100 \mathrm{~d}$ ) of VAP in subjects randomized to the PP treatment arm. In a prematurely terminated RCT in which the majority of subjects had ARDS ${ }_{\mathrm{p}}$, Mancebo et al ${ }^{133}$ found no difference in the prevalence of VAP between PP (18.4\%) and SP $(15 \%, P=.65)$. In addition, a 9-year, retrospective, multicenter study of $\mathrm{PP}$ analyzed $>2,400$ subjects with a $\mathrm{P}_{\mathrm{aO}_{2}} / \mathrm{F}_{\mathrm{IO}_{2}}<300 \mathrm{~mm} \mathrm{Hg}$ and reported that PP had no effect on the incidence of VAP. ${ }^{134}$ Therefore, the preponderance of higher-level evidence suggests that PP may reduce the incidence of VAP in a variety of patients with acute respiratory failure. The data also suggest that as a precaution, patients placed in PP should be managed in the reverse-Trendelenburg position to further reduce the chances of gastroesophageal reflux and aspiration risk.

\section{Effects of PP on Alveolar Fluid Clearance}

Enhanced clearance of extravascular lung water also has been reported with PP and may partly explain why some patients exhibit improved oxygenation only after prolonged periods in that position. ${ }^{88}$ Enhanced fluid clearance also has been observed in patients with ARDS who are $\mathrm{P}_{\mathrm{OO}_{2}}$ responders to a recruitment maneuver. ${ }^{135}$ Alveolar recruitment might increase pulmonary edema clearance by simultaneously recruiting aquaporins in the alveolar walls as 
well as increasing total alveolar surface area available for fluid reabsorption. ${ }^{135}$ In pediatric subjects with ARDS, increased oxygenation was associated with a two-thirds reduction in positive fluid balance during the PP period. ${ }^{109}$ Extravascular lung water and alveolar protein measurement during PP have not been studied. This might be an underappreciated aspect of both gas exchange and lung mechanics improvement with PP in ARDS.

\section{Hemodynamic Effects of PP}

Hypotension associated with PP during surgery occurs frequently and is attributed to decreased venous return from the combined effects of intravascular fluid depletion and elevated IAP that compresses the inferior vena cava. ${ }^{39,136}$ However, in hemodynamically stable subjects PP does not cause significant changes in systemic blood pressure or cardiac index. $24,29,31,33,35,36,80-82,84-86,88,91,105 \mathrm{In}$ addition, most studies found either no differences $24,31,33,35,36,80-82,85$ or small increases in central venous pressure, pulmonary arterial pressure, pulmonary arterial occlusion pressures, or pulmonary vascular resistance during PP. ${ }^{29,91,113}$ This suggests that the increased vascular pressures may reflect the combined effects of reduced $\mathrm{C}_{\mathrm{CW}}$ and positive-pressure ventilation during PP. ${ }^{137}$ Notably, clinical studies have enrolled only subjects with stable hemodynamic function, so that a thorough hemodynamic assessment is important before utilizing PP. For example, patients with a history of myocardial infarction or ischemic heart disease are known to be susceptible to systolic and diastolic dysfunction when placed in PP. ${ }^{138}$

\section{Hemodynamic Effects of IAP During PP}

Increased IAP during PP has been a particular concern and is influenced by the type of support surface used. Michelet et al ${ }^{139}$ reported that air-cushioned mattresses (vs foam mattresses) prevented an increase in IAP and preserved hepatic perfusion but had no impact on hemodynamics, extravascular lung water, or pulmonary gas exchange. Hering et $\mathrm{al}^{140}$ found that air-cushioned mattresses without abdominal support caused IAP to increase by $2 \mathrm{~mm} \mathrm{Hg}$, coinciding with a small increase in cardiac index that maintained adequate renal function.

These results were reproduced in a subsequent study by Hering et al, ${ }^{141}$ wherein the same $2-\mathrm{mm} \mathrm{Hg}$ increase in IAP did not affect intrathoracic blood volume, hepatic function, or gastric mucosal perfusion. The authors concluded that impaired hemodynamic function may be more prevalent in patients with inadequate intravascular volume status. ${ }^{140,141}$ Similar findings using an air-cushioned mattress without abdominal support were reported by Matejovic et al, ${ }^{142}$ wherein PP caused no change in hemodynamics, abdominal perfusion pressure, hepatosplanchnic perfusion, hepatic function, or urine output. PP produced a significant rise in IAP $(>3 \mathrm{~mm} \mathrm{Hg})$ in only $18 \%$ of subjects. However, none of the subjects in these studies had intra-abdominal hypertension $(\geq 15 \mathrm{~mm} \mathrm{Hg}$ ) so that these results cannot be generalized to patients with highly elevated IAP.

\section{Effects of PP on Right Heart Function in ARDS}

Acute pulmonary hypertension is a common feature of ARDS and has multiple sources, including hypoxemia, hypercapnia, acidosis, and pulmonary vascular obstruction from interstitial edema and disseminated arterial and microvascular embolization. ${ }^{143-146}$ Acute cor pulmonale occurs in $22-25 \%$ of patients with ARDS and increases to $50 \%$ in those with a $\mathrm{P}_{\mathrm{aO}_{2}} / \mathrm{F}_{\mathrm{IO}_{2}}<100 \mathrm{~mm} \mathrm{Hg} .{ }^{147}$ Acute cor pulmonale has been independently associated with both high driving pressures during mechanical ventilation and infectious causes of ARDS; the presence of acute cor pulmonale increases mortality from 36 to $60 \% .^{148}$

In a patient with severe ARDS, Legras et al ${ }^{125}$ reported that PP caused an instantaneous near cessation of shunting across the foramen ovale that coincided with decreased pulmonary vascular pressures. PP increased $\mathrm{P}_{\mathrm{aO}} / \mathrm{F}_{\mathrm{IO}_{2}}$ from 59 to $278 \mathrm{~mm} \mathrm{Hg}$, and $\mathrm{P}_{\mathrm{aCO}_{2}}$ decreased from 54 to $39 \mathrm{~mm} \mathrm{Hg}$. Dramatic decreases in pulmonary vascular resistance index (from 514 to 234 dynes $5 / \mathrm{cm}^{5} / \mathrm{m}^{2}$ ) and right ventricular dimensions in ARDS have been reported with PP, coinciding with increased $\mathrm{P}_{\mathrm{aO}_{2}} / \mathrm{F}_{\mathrm{IO}_{2}} \cdot{ }^{28}$ Similarly, in severe ARDS with documented acute cor pulmonale, PP substantially increased $\mathrm{P}_{\mathrm{aO}_{2}} / \mathrm{F}_{\mathrm{IO}_{2}}$ and decreased $\mathrm{P}_{\mathrm{aCO}}$, which coincided with decreased right ventricular size and increased cardiac index. ${ }^{149}$

Approximately $19 \%$ of patients with ARDS have a moderate to large patent foremen ovale coinciding with either increased right ventricular size or acute cor pulmonale that is exacerbated by PEEP. ${ }^{150}$ The prevalence of both acute cor pulmonale and patent foremen ovale in ARDS and their association with increased mortality might partially explain the mortality benefit recently reported in severe ARDS.

\section{Effects of PP in Acute Brain Injury}

Two studies examined how PP affects neurovascular function and brain tissue oxygenation in subjects with acute brain injury and ARDS or pneumonia. Reinprecht et al ${ }^{100}$ used PP sessions of $16 \mathrm{~h}$ in subjects with subarachnoid hemorrhage and ARDS. Although intracranial pressure (ICP) was moderately increased (from $10 \pm 4$ to $16 \pm 4 \mathrm{~mm} \mathrm{Hg}$ ) and cerebral perfusion pressure decreased (from $74 \pm 8$ to $67 \pm 7 \mathrm{~mm} \mathrm{Hg}$ ), $\mathrm{P}_{\mathrm{aO}_{2}} / \mathrm{F}_{\mathrm{IO}_{2}}$ markedly increased (range of $37-183 \mathrm{~mm} \mathrm{Hg}$ ) in $88 \%$ of subjects. This resulted in a significant increase in brain tissue oxy- 


\section{PRONe Position IN ARDS}

gen tension (from $27 \pm 4$ to $35 \pm 5 \mathrm{~mm} \mathrm{Hg}$ ). Similar findings of improved $\mathrm{P}_{\mathrm{aO}_{2}}$ and modestly increased ICP (from $12 \pm 6$ to $15 \pm 4 \mathrm{~mm} \mathrm{Hg}$ ) with PP were reported by Nekludov et al ${ }^{101}$ in subjects with acute brain injury and pneumonia. Mean arterial pressure increased markedly compared with ICP, so that cerebral perfusion pressure increased from $66 \pm 7$ to $73 \pm 8 \mathrm{~mm} \mathrm{Hg}$, along with a $24 \%$ increase in $\mathrm{P}_{\mathrm{aO}}$.

Importantly, these studies enrolled subjects in whom ICP and coronary perfusion pressure were well controlled with vasopressors, mannitol, and ventricular drainage. Despite these therapies, Reinprecht et al ${ }^{100}$ found that subjects placed in PP had a higher occurrence of ICP $>20 \mathrm{~mm} \mathrm{Hg}$ (18\% vs $2 \%$ in SP) and cerebral perfusion pressure $<60 \mathrm{~mm} \mathrm{Hg}(22 \%$ vs $8 \%)$. However, PP reduced the incidence of brain tissue oxygen tension $<20 \mathrm{~mm} \mathrm{Hg}$ from $33 \%$ in SP to $10 \%$. Using PP in patients with acute brain injury and ARDS should be approached with caution and restricted to those in whom baseline ICP can be maintained $<20 \mathrm{~mm} \mathrm{Hg}$ and who are hemodynamically stable.

\section{Effects of PP on VILI in Experimental and Clinical ARDS}

In healthy animals, the dependent, nondependent, and middle lung regions possess differing stress-strain characteristics under both static and dynamic conditions due to the effects of gravity, regional traction, and regional compression. Under static conditions in SP, the lungs are inherently inhomogeneous. Nondependent regions exhibit a steep stress-strain curve during inflation, whereas the stressstrain curve rises more gradually in dependent regions. During PP, regional differences in stress-strain ratios between lung regions are more uniform, and within each region, stress rises more gradually relative to strain. ${ }^{151}$

Several experimental models of ARDS, both with and without VILI, have examined whether PP confers a lungprotective benefit compared with SP. ${ }^{152-156}$ Broccard et al ${ }^{152}$ combined oleic acid with high-stretch injury, producing similar degrees of pulmonary edema formation throughout the lung regardless of position. However, histologic injury was less severe and less extensive in dependent lung regions with PP. In a high-stretch low-PEEP VILI model, ${ }^{53}$ PP resulted in milder, more homogeneously distributed injury. Pulmonary edema and histologic injury were approximately $30 \%$ less than with SP. In a similar study, Nakos et al ${ }^{155}$ also reported more evenly distributed histopathological changes throughout the lung, and lung injury was approximately $50 \%$ less than with SP.

PP also delays the onset of VILI by $50-80 \% .^{153,154}$ This was attributable to more even lung density distribution in the dorsoventral axis. The lungs appeared slightly shorter and wider with a corresponding $28 \%$ reduction in estimated lung strain, consistent with more homogeneous pleu- ral pressure distribution in PP. ${ }^{154}$ Santana et al ${ }^{156}$ found that PP resulted in decreased lung elastance and viscoelastance associated with a more homogeneous distribution of alveolar air/tissue ratios.

One of the most consequential findings was made by Nakos et al, ${ }^{155}$ who measured the apoptopic index in the lungs, liver, kidneys, small intestine, and diaphragm. After only 90 min of exposure to a high-stretch low-PEEP VILI model, animals in SP had significantly greater apoptosis scores in the lungs, liver, and diaphragm, with trends toward higher scores in the other organs (Fig. 5). Apoptosis ("programmed cell death") is caused by signaling molecules released within or between organs. This may partly explain why mortality in ARDS results from multiorgan system failure rather than refractory hypoxemia. Pulmonary translocation and dissemination of these signaling molecules (as well as bacteria and pro-inflammatory mediators) to the systemic circulation is believed to be the responsible mechanism. ${ }^{157,158}$

Only 2 clinical studies have compared pro-inflammatory mediator expression between SP and PP. Papazian et al ${ }^{159}$ discovered that PP reduced both neutrophil levels and pro-inflammatory mediator levels of IL- $1 \beta$, IL-6, and IL-8 in bronchoalveolar lavage fluid compared with SP. Of particular interest is IL-8 (a chemo-attractant cytokine for neutrophils), which is secreted by the alveolar epithelium and macrophages in response to excessive stretch. Lung injury is perpetuated from neutrophil infiltration and subsequent proteolytic enzyme release. ${ }^{160}$ This underscores the importance of PP in ameliorating VILI by effecting more homogeneous pleural pressure gradients and more uniform regional EELV, $\mathrm{V}_{\mathrm{T}}$ distribution, and strain-stress relationships throughout the lungs.

Chan et al $^{161}$ examined cytokine profiles in ARDS between PP and SP and their impact upon early mortality at 2 time points. Twenty-two subjects with community-acquired pneumonia-associated ARDS were randomized to $\mathrm{PP}$ or SP with both groups receiving lung-protective ventilation. Plasma IL-6 levels were measured at baseline, $24 \mathrm{~h}$, and $72 \mathrm{~h}$. Baseline IL-6 levels were higher in the PP versus $\mathrm{SP}$ arms $(396 \pm 31 \mathrm{pg} / \mathrm{mL}$ vs $323 \pm 50 \mathrm{pg} / \mathrm{mL}$, respectively) but steadily declined over $72 \mathrm{~h}$ with $\mathrm{PP}$ $(196 \pm 47 \mathrm{pg} / \mathrm{mL})$ compared with SP $(278 \pm 53 \mathrm{pg} / \mathrm{mL})$. IL-6 levels predicted mortality at $14 \mathrm{~d}$ for all subjects (18\% in PP arm; $27 \%$ in SP). IL-6 levels in communityacquired pneumonia are directly associated with the disease severity. ${ }^{162}$ PP may reduce VILI risk through improved oxygenation that decreases exposure to hyperoxia, a powerful stimulant for IL-6 expression. ${ }^{163}$ Although 28-d mortality was not different between treatment arms (36\%), early mortality might be impacted through this mechanism. Interestingly, IL-6 levels typically peak at approximately $10 \mathrm{~d}$ of exposure to hyperoxia, ${ }^{163}$ inviting specu- 


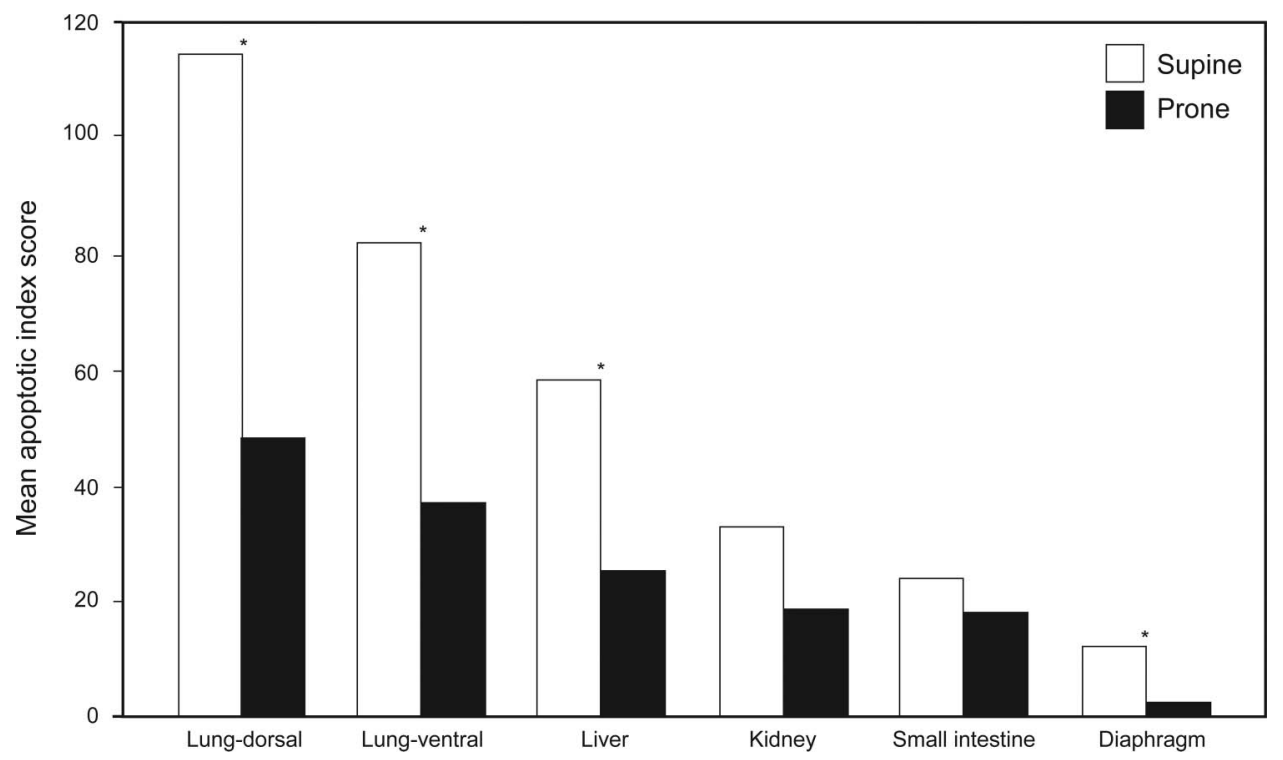

Fig. 5. Differences in mean apoptotic index scores between the supine and prone position in an animal model of high-stretch, ventilatorinduced lung injury. ${ }^{*}=\mathrm{P}<.05$. Data from Reference 155.

lation that excessive expression of pro-inflammatory mediators might influence early mortality in ARDS.

\section{Randomized Controlled Trials of PP}

Since 2001, there have been 10 RCTs comparing PP with SP on outcomes either in adult subjects with ARDS, ${ }^{6,117-119,132,133,164}$ pediatric subjects with ARDS, 120 or comatose subjects as prophylaxis for ARDS. ${ }^{131}$ Interpreting these studies has been difficult because the methodologies and end points differed considerably. For ethical reasons, several studies ${ }^{117-119,133,164}$ allowed cross-over from SP to PP for rescue therapy, and 3 studies included $8 \%,{ }^{117} 12 \%,,^{164}$ and $21 \%{ }^{118}$ of subjects originally assigned to the SP treatment arm. In one study, lack of sufficient staffing to perform turning maneuvers affected $27 \%$ of subjects assigned to the PP study arm, ${ }^{117}$ whereas in another, adherence to 8 -h prone sessions was violated in $25 \%$ of subjects. ${ }^{118}$

Studies of adult ARDS published from 2001 to 2005 were noteworthy for limited duration of PP sessions (4$8 \mathrm{~h} / \mathrm{d}),{ }^{117,118,131,132}$ including subjects with mild or moderate hypoxemia ${ }^{117,118,131,132}$ or those with acute respiratory failure other than ARDS, ${ }^{117}$ relatively large $\mathrm{V}_{\mathrm{T}}$ values $(10 \mathrm{~mL} / \mathrm{kg}),{ }^{117,118,131}$ and lack of ancillary protocols to standardize care. ${ }^{117,118,161}$ Also, in some studies, it was unclear how long subjects had ARDS prior to enrollment. ${ }^{117,118}$ In the 4 major adult studies published after 2005, subjects were enrolled within $72 \mathrm{~h}$ of ARDS onset, and the studies were delimited to those with more severe ARDS. 6,119,133,164 In addition, these studies targeted longer durations of PP (20 h/d); adhered more closely to lung- protective ventilation, including $\mathrm{V}_{\mathrm{T}}$ of $6-8 \mathrm{~mL} / \mathrm{kg}$ with higher levels of PEEP $\left(\geq 10 \mathrm{~cm} \mathrm{H}_{2} \mathrm{O}\right)$; and relied more on protocolized care both for ventilator management and sedation. The most rigorous of these studies (PROSEVA) in terms of detailed, regimented, protocolized care also was the one that provided the most impressive positive results. ${ }^{6}$

Many studies were not powered to assess mortality either through design ${ }^{120,131,132,161}$ or difficulty maintaining sufficient enrollment. ${ }^{117-119,133}$ Therefore, interpreting mortality has been difficult. Despite these limitations, several studies suggested the possibility of improved mortality with PP in those with severe ARDS. A post hoc analysis of the Prone-Supine I study ${ }^{117}$ found that subjects with $\mathrm{P}_{\mathrm{aO}_{2}} / \mathrm{F}_{\mathrm{IO}_{2}} \leq 88 \mathrm{~mm} \mathrm{Hg}$ had reduced mortality with PP versus SP (23\% vs $47 \%$ respectively; relative risk $=0.49$, $95 \%$ CI $=0.25-0.95)$. Likewise, in the Prone-Supine II study, 164 the cohort with a $\mathrm{P}_{\mathrm{aO}_{2}} / \mathrm{F}_{\mathrm{IO}_{2}}<100 \mathrm{~mm} \mathrm{Hg}$ treated with PP also had a trend toward improved ICU mortality compared with SP (45.9 vs $55.3 \%$ respectively, $P=.25$ ).

Mancebo et $\mathrm{al}^{133}$ found a trend toward higher severe acute physiology scores (SAPS II) in the PP versus SP study arms (43 vs $38, P=.08$ ) but an opposite trend toward lower ICU mortality in subjects randomized to PP ( $43 \%$ vs $58 \%$ respectively, $P=.12$ ). In addition, delayed initiation of PP from ARDS onset was a significant factor in predicting mortality (odds ratio of $2.83,95 \%$ CI: $1.63-$ 4.90, $P<.001) .{ }^{133}$ Fernandez et al ${ }^{119}$ found a similar trend favoring lower 60-d mortality in the PP versus SP study arms $(38 \%$ vs $53 \%, P=.3)$. Even the smallest studies ${ }^{131,132}$ reported trends toward lower 28 -d mortality with PP versus SP (5\% vs $16 \%{ }^{132}$ and $28 \%$ vs $\left.46 \%{ }^{131}\right)$. 
Most recently, the PROSEVA study group 6 enrolled 466 subjects with severe ARDS $\left(\mathrm{P}_{\mathrm{aO}_{2}} / \mathrm{F}_{\mathrm{IO}_{2}}<150 \mathrm{~mm} \mathrm{Hg}\right.$ on $\mathrm{F}_{\mathrm{IO}_{2}}>0.6$ and PEEP $>5 \mathrm{~cm} \mathrm{H} \mathrm{H}_{2} \mathrm{O}$ ). Explicit protocols were used for ventilator management, rescue therapies, weaning, sedation, and paralytics. Subjects were randomized within $33 \mathrm{~h}$ of intubation, and PP was sustained for an average of $17 \mathrm{~h} / \mathrm{d}$. Mortality at 28 and $90 \mathrm{~d}$ was significantly lower with PP versus SP (16\% vs 33\%, respectively, $P<.001$, and $21 \%$ vs $41 \%$, respectively, $P<.001$ ). Both ventilator-free days at 28 and $90 \mathrm{~d}$ also were greater with PP versus SP $(14 \mathrm{~d}$ vs $10 \mathrm{~d}$, respectively, $P<.001$; $57 \mathrm{~d}$ vs $43 \mathrm{~d}$, respectively, $P<.001$ ).

\section{Meta-Analysis of RCTs}

There have been 6 formal systematic reviews and metaanalyses of RCTs investigating PP published, ${ }^{7-11,13}$ and a "patient-level meta-analysis." 12 In brief, meta-analysis pools data from therapeutic trials investigating outcomes in the same disease that have used similar designs and that either were underpowered or have produced inconsistent results. The intention of meta-analysis is to determine whether analysis of the pooled data can provide clear, statistically significant evidence that a therapeutic intervention is indeed effective. As described above, the difficulty in performing a credible meta-analysis of RCTs is confronting the methodological variability between studies (eg, duration of PP, initiation of PP relative to the onset of ARDS, severity of ARDS, PEEP and $\mathrm{V}_{\mathrm{T}}$ management, use of protocols, non-uniform study end points, etc). A brief summary of these findings and their implications for clinical practice are provided below.

The primary focus of the meta-analysis studies was assessing the impact of PP on mortality, and each study tended to have different approaches to examining the problem. When all subjects are considered across all RCTs, PP has not shown mortality benefit compared with SP despite a clear improvement in oxygenation. However, when the meta-analyses restricted their focus to subjects managed with smaller $\mathrm{V}_{\mathrm{T}}$ levels $(\leq 8 \mathrm{~mL} / \mathrm{kg}),{ }^{11}$ higher PEEP levels $\left(10-13 \mathrm{~cm} \mathrm{H}_{2} \mathrm{O}\right),{ }^{10}$ longer duration of PP sessions $(>10-$ $12 \mathrm{~h} /$ session), ${ }^{9-11}$ and enrollment delimited to more severe disease $\left(\mathrm{P}_{\mathrm{aO}_{2}} / \mathrm{F}_{\mathrm{IO}_{2}} \leq 150 \mathrm{~mm} \mathrm{Hg}\right), 9,10,13 \mathrm{PP}$ clearly reduced mortality risk by $34 \%, 43 \%, 29-38 \%$, and $15-29 \%$, respectively (Table 1). It is important to emphasize that later PP studies enrolled subjects during early ARDS (exudative phase) within 25-72 h after diagnosis, $6,119,120,133,164$ when there is a higher likelihood that PP might ameliorate VILI and right heart strain and therefore a greater probability for reducing mortality.

\section{Adverse Events Associated With PP}

The meta-analyses of RCTs also found a significantly higher risk for developing pressure ulcerations with PP
$(29-49 \%), 9,10,13$ as well as airway complications associated with endotracheal tube obstruction from florid secretion mobilization $(58-218 \%) .9,10$ The risk for developing tachycardia, bradycardia, or cardiac arrest with PP was not significantly different from the risk for subjects managed with SP. ${ }^{10}$

These findings are consistent with reports of similar complications in the observational studies. Fifteen studies involving 297 subjects found no increased risk for adverse events related to PP. $2,3,32,35,36,56,80,81,83,84,90,91,105,115,121$ Fifteen other observational studies involving 401 subjects did report an increased risk for adverse events associated with PP. ${ }^{24,26,27,29-31,33,82,85-89,92,108}$ Consistent with the metaanalysis of RCTs, ${ }^{9,10,13}$ pressure ulcerations (particularly to the forehead and anterior chest wall) appeared within $24 \mathrm{~h}$ of PP. ${ }^{85,113}$ Facial edema rapidly reversed upon placement back in $\mathrm{SP}^{26,31,33,84,88,89}$ and could be ameliorated by placing subjects in reverse-Trendelenburg while in PP.105

Other reported complications are relatively infrequent and included enteral feeding intolerance $(9-25 \%), 26,31,89$ significant oxygen desaturation $(6-8 \%),{ }^{82,92}$ loss of intravascular lines (3-12\%), $, 25,29,82$ and accidental extubation $(1-3 \%) .{ }^{24,82}$ The incidence of hemodynamic instability is approximately $2-4 \% .^{24,85,86,108}$ One observational study reported a cardiac arrest associated with $\mathrm{PP},{ }^{30}$ whereas Guérin et $\mathrm{al}^{6}$ found a significantly higher incidence of cardiac arrest in subjects assigned to the SP group. Hypotension was noted to be a transient occurrence that occurred most frequently during the turning procedure, when subjects were placed briefly in the lateral decubitus position. ${ }^{85}$

In severe polytrauma, Offner et $\mathrm{al}^{30}$ reported significant complications, including midline abdominal wound dehiscence and severe pressure necrosis on the face and chest despite diligent, proactive skin care. These complications tended to occur more frequently in the elderly as well as those with anasarca or those requiring high-dose vasopressors. L'Her et al ${ }^{89}$ reported a $45 \%$ incidence of pressure ulcers, with $20 \%$ being severe (Stage III or IV). Stocker et $\mathrm{al}^{27}$ reported a case of infectious ulceration in the eyes during PP that required corneal transplantation. Severe bilateral breast necrosis after only $24 \mathrm{~h}$ in PP was reported in a woman with silicone breast implants. ${ }^{165}$ This case was noteworthy for several risk factors, including advanced age $(73 \mathrm{y})$, high vasopressor requirements, and the fact that the implants were fixed by fibrous tissue.

In a sub-study associated with the PROSEVA trial, 166 subjects allocated to the PP study arm had a trend toward a higher incidence of pressure ulcers (20.8 vs14.3/1,000 d, $P=.06)$. Independent risk factors included age $>60$ y (odds ratio $1.53, P=.002$ ) and body mass index $>28.4$ $\mathrm{kg} / \mathrm{m}^{2}(1.98, P=.004)$. A retrospective case series of 21 patients with H1N1-associated ARDS reported 5 patients who developed secondary sclerosing cholangitis during prolonged PP. ${ }^{167}$ This particular complication is associated 


\section{PRONe Position IN ARDS}

Table 1. Meta-Analysis of Randomized Clinical Trials of Prone Positioning in ARDS

\begin{tabular}{|c|c|c|c|c|}
\hline Study & Trials & $N$ & Primary Findings: PP vs SP & OR $(95 \% \mathrm{CI})$ or WMD, $P$ \\
\hline \multirow[t]{5}{*}{ Abroug et $\mathrm{al}^{7}$} & 5 & 1,372 & Mortality: $34.9 \%$ vs $35.5 \%$ & $0.97(0.77-1.22)$ \\
\hline & & & VAP & $0.77(0.57-1.04), P=.09$ \\
\hline & & & Airway compromise: $10.5 \%$ vs $10.4 \%$ & $1.01(0.71-1.43), P=.95$ \\
\hline & & & Pressure ulcers/facial edema: $41 \%$ vs $34 \%$ & $1.35(1.08-1.69), P=.007$ \\
\hline & & & $\uparrow \mathrm{P}_{\mathrm{aO}_{2}} / \mathrm{F}_{\mathrm{IO}_{2}}$ & $25 \mathrm{~mm} \mathrm{Hg}(15-35), P<.001$ \\
\hline \multirow[t]{6}{*}{ Alsaghir et $\mathrm{al}^{8}$} & 4 & 1,271 & 90-d all mortality & $0.99(0.77-1.79)$ \\
\hline & & & Early $\uparrow \mathrm{P}_{\mathrm{aO}_{2}} / \mathrm{F}_{\mathrm{IO}_{2}}$ & 52 mm Hg (7-96) \\
\hline & & & Intermediate $\uparrow \mathrm{P}_{\mathrm{aO}_{2}} / \mathrm{F}_{\mathrm{IO}_{2}}$ & 44 mm Hg (14-74) \\
\hline & & & Late $\uparrow \mathrm{P}_{\mathrm{aO}_{2}} / \mathrm{F}_{\mathrm{IO}_{2}}$ & $25 \mathrm{~mm} \mathrm{Hg}(15-34)$ \\
\hline & & & Total ventilator days & $-0.42(-1.56$ to 0.72$)$ \\
\hline & & & VAP & $0.78 \%(0.40-1.51)$ \\
\hline \multirow[t]{9}{*}{ Sud et $\mathrm{al}^{13}$} & 10 & 1,867 & & \\
\hline & & & Mortality: all subjects & $0.97(0.88-1.07)$ \\
\hline & 7 & 495 & Cohort: $\mathrm{P}_{\mathrm{aO}_{2}} / \mathrm{F}_{\mathrm{IO}_{2}}<100 \mathrm{~mm} \mathrm{Hg} *$ & $0.85(0.74-0.98), P=.02$ \\
\hline & 7 & 852 & $\begin{array}{l}\text { Cohort: } \mathrm{P}_{\mathrm{aO}_{2}} / \mathrm{F}_{\mathrm{IO}_{2}} \geq 100 \mathrm{~mm} \mathrm{Hg} * \\
\text { Oxygenation: } \uparrow \mathrm{P}_{\mathrm{aO}_{2}} / \mathrm{F}_{\mathrm{IO}_{2}}: 27-39 \%\end{array}$ & $1.04(0.89-1.22), P=.60$ \\
\hline & 8 & 1,066 & VAP & $0.81(0.67-1.00), P=.05$ \\
\hline & 8 & 1,588 & Total ventilator days & $-0.7(-2.01$ to 0.62$), P=.30$ \\
\hline & 7 & 1,279 & Pressure ulcers & $1.29(1.16-1.44), P<.001$ \\
\hline & 7 & 1,351 & ETT obstruction & $1.58(1.24-2.01), P<.001$ \\
\hline & 8 & 886 & CT dislodgement & $3.14(1.02-9.69)$ \\
\hline \multirow[t]{13}{*}{ Lee et $\mathrm{al}^{9}$} & 11 & 2,246 & & \\
\hline & & & Mortality: overall $41.5 \%$ vs $46.2 \%$ & $0.77(0.59-0.99), P=.039$ \\
\hline & & & $\mathrm{PP}<10 \mathrm{~h} /$ session & $1.04(0.80-1.36), P=.76$ \\
\hline & & & $\mathrm{PP}>10 \mathrm{~h} /$ session & $0.62(0.48-0.79), P<.001$ \\
\hline & & & ALI/AHRF & $1.02(0.76-1.36), P=.92$ \\
\hline & & & $\mathrm{P}_{\mathrm{aO}_{2}} / \mathrm{F}_{\mathrm{IO}_{2}} \leq 150 \mathrm{~mm} \mathrm{Hg}$ & $0.72(0.55-0.95), P=.02$ \\
\hline & & & Pressure ulcers & $1.49(1.18-1.89), P=.001$ \\
\hline & & & Airway emergencies $\dagger$ & $1.55(1.10-2.17), P=.01$ \\
\hline & & & ETT obstruction (as sole factor) & $2.16(1.53-3.05), P<.001$ \\
\hline & & & VAP & $0.76(0.44-1.33), P=.34$ \\
\hline & & & Tachycardia/bradycardia & $1.08(0.78-1.50), P=.64$ \\
\hline & & & Cardiac arrest & $0.74(0.47-1.17), P=.20$ \\
\hline & & & Pneumothoraces & $0.77(0.46-1.30), P=.33$ \\
\hline \multirow[t]{8}{*}{ Hu et al ${ }^{10}$} & 9 & 2,242 & & \\
\hline & & 1,600 & Mortality: 90-d all ARDS: $\mathrm{P}_{\mathrm{aO}_{2}} / \mathrm{F}_{\mathrm{IO}_{2}} \leq 300 \mathrm{~mm} \mathrm{Hg}$ & $0.85(0.62-1.18), P=.33$ \\
\hline & & 508 & 28-30-d when $\mathrm{P}_{\mathrm{aO}_{2}} / \mathrm{F}_{\mathrm{IO}_{2}}<100 \mathrm{~mm} \mathrm{Hg}$ & $0.71(0.57-0.89), P=.003$ \\
\hline & & 521 & 28-30-d when $\mathrm{P}_{\mathrm{aO}} / \mathrm{F}_{\mathrm{IO}_{2}}: 101-200 \mathrm{~mm} \mathrm{Hg}$ & $0.72(0.39-1.34), P=.30$ \\
\hline & & 506 & 90-d with PEEP $10-13 \mathrm{~cm} \mathrm{H}_{2} \mathrm{O}$ & $0.57(0.43-0.75), P<.001$ \\
\hline & & 1,094 & 90-d with PEEP $<10 \mathrm{~cm} \mathrm{H}_{2} \mathrm{O}$ & $1.04(0.92-1.18), P=.56$ \\
\hline & & 1,067 & 28-30-d mortality PP $>12 \mathrm{~h} / \mathrm{session}$ & $0.73(0.54-0.99), P=.04$ \\
\hline & & 1,095 & 28-30-d mortality PP $\leq 12 \mathrm{~h} /$ session & $1.04(0.89-1.22), P=.60$ \\
\hline \multirow[t]{7}{*}{ Beitler et al ${ }^{11}$} & 7 & 2,119 & & \\
\hline & & & Mortality: overall & $0.83(0.68-1.02), P=.07$ \\
\hline & & & $\mathrm{V}_{\mathrm{T}} \leq 8 \mathrm{~mL} / \mathrm{kg}$ PBW & $0.66(0.50-0.86), P=.002$ \\
\hline & & & $\mathrm{V}_{\mathrm{T}}>8 \mathrm{~mL} / \mathrm{kg}$ PBW & $1.00(0.88-1.13), P=.95$ \\
\hline & & & $\downarrow 1 \mathrm{~mL} / \mathrm{kg}$ PBW in baseline $\mathrm{V}_{\mathrm{T}}$ & $\downarrow$ RR by $16.7 \%$ (6.1-28.3), $P=.001$ \\
\hline & & & $\mathrm{PP}>12 \mathrm{~h} /$ session & $0.71(0.56-0.90), P=.004$ \\
\hline & & & $\mathrm{PP}<12 \mathrm{~h} /$ session & $1.05(0.92-1.19), P=.47$ \\
\hline \multicolumn{5}{|c|}{$\begin{array}{l}\text { * Estimate excludes subjects with acute hypoxemic respiratory failure not caused by ARDS enrolled into some studies.90 } \\
\dagger \text { Airway emergencies included accidental extubation, endotracheal tube migration, and endotracheal tube obstruction. }\end{array}$} \\
\hline \multicolumn{5}{|c|}{$\begin{array}{l}\dagger \text { Airway emergencies included accidental extubation, endotracheal tube migration, and endotracheal tube obstruction. } \\
\mathrm{PP}=\text { prone position }\end{array}$} \\
\hline \multicolumn{5}{|c|}{$\mathrm{SP}=$ supine position } \\
\hline \multicolumn{5}{|c|}{$\mathrm{OR}=$ odds ratio } \\
\hline \multicolumn{5}{|c|}{ WMD $=$ weighted mean difference } \\
\hline \multicolumn{5}{|c|}{ VAP $=$ ventilator-associated pneumonia } \\
\hline \multirow{2}{*}{\multicolumn{5}{|c|}{$\begin{array}{l}\mathrm{ETT}=\text { endotracheal tube } \\
\mathrm{CT}=\text { chest tube }\end{array}$}} \\
\hline & & & & \\
\hline \multicolumn{5}{|c|}{$\mathrm{ALI}=$ acute lung injury (ie, $\left.\mathrm{P}_{\mathrm{aO}_{2}} / \mathrm{F}_{\mathrm{IO}_{2}}>200 \mathrm{~mm} \mathrm{Hg}\right)$} \\
\hline \multicolumn{5}{|c|}{$\begin{array}{l}\text { AHRF }=\text { acute hypoxemic respiratory failure (non-ARDS) } \\
\text { PBW }=\text { predicted body weight }\end{array}$} \\
\hline $\mathrm{PBW}=$ predicted $\mathrm{l}$ & & & & \\
\hline
\end{tabular}


with high PEEP and vasopressor therapy, resulting in biliary duct ischemia from hypoperfusion of the peribiliary vascular plexis. All 21 subjects had severe ARDS requiring PEEP $>15 \mathrm{~cm} \mathrm{H}_{2} \mathrm{O}$ and PP sessions of $12 \mathrm{~h} / \mathrm{d}$. The 5 subjects who developed severe cholangitis were morbidly obese (body mass index of $37 \pm 6 \mathrm{~kg} / \mathrm{m}^{2}$ ) and required daily PP for several weeks.

\section{Incorporating PP Into Bundled Care}

PP improves oxygenation over a variable time course that may reach a plateau after $12-24 \mathrm{~h},{ }^{26,79,88,89}$ but in some cases, improvement continues for $30-55 \mathrm{~h}^{97,98}$ This has been attributed to the interplay between several factors, including increased IAP and abnormal $\mathrm{C}_{\mathrm{CW}}$, compression atelectasis, and persistent small airway closure despite high levels of PEEP (ie, $14 \mathrm{~cm} \mathrm{H}_{2} \mathrm{O}$ ). ${ }^{168}$ Airway closure is both asynchronous in onset and unevenly distributed, particularly in dependent lung regions that delay in opening, close quickly, and have a lower EELV. ${ }^{169}$

Effective lung recruitment requires a combination of pressure and time, with time mostly reflecting the influence of airway closure and stress-relaxation (tissue yielding) characteristics of the lung and chest wall. ${ }^{170}$ Reopening collapsed small airways is a dynamic process with a variable time course. ${ }^{171}$ To recruit collapsed small airways, applied airway pressure must overcome the surface tension, viscosity, and film thickness of the airway lining fluid, which in turn is influenced by airway radius, axial wall traction exerted by the surrounding alveoli, and the presence of functional surfactant. ${ }^{171,172}$ Increased lining fluid surface tension requires higher airway pressures to open collapsed airways, whereas increased lining fluid viscosity increases the time necessary to open sequentially collapsed airways. ${ }^{172}$

\section{High-Level PEEP and Recruitment Maneuver}

In a subset of patients with particularly severe ARDS, PP by itself may be insufficient to stabilize gas exchange and minimize the risk of VILI. Developing a multifaceted approach that incorporates high-level PEEP, recruitment maneuvers, and inhaled vasodilators may enhance the effectiveness of PP and expedite gas exchange stabilization. This may reduce the likelihood for adverse effects associated with prolonged exposure to toxic levels of oxygen, high PEEP, and PP. Several prospective studies have compared the impact of PP on the effectiveness of PEEP ${ }^{91}$ and recruitment maneuvers ${ }^{124,173-175}$ to improve pulmonary gas exchange and mechanics in severe ARDS.

Gainnier et $\mathrm{al}^{91}$ demonstrated that PEEP and PP have an additive effect on lung recruitment but also are mediated by lung injury characteristics: diffusely distributed injury versus restricted injury either to the dependent regions (lobar) or otherwise localized (patchy). Subjects with localized infiltrates showed relatively modest improvement in $\mathrm{P}_{\mathrm{aO}} / \mathrm{F}_{\mathrm{IO}_{2}}$ when PEEP was adjusted stepwise from 0 to $15 \mathrm{~cm} \mathrm{H}_{2} \mathrm{O}$ either in $\mathrm{SP}(\sim 110-130 \mathrm{~mm} \mathrm{Hg})$ or PP $(\sim 160$ $220 \mathrm{~mm} \mathrm{Hg}$ ). In contrast, subjects with diffuse injury responded to the same PEEP adjustments by increasing $\mathrm{P}_{\mathrm{aO}_{2}} / \mathrm{F}_{\mathrm{IO}_{2}}$ from 60 to $160 \mathrm{~mm} \mathrm{Hg}$ (SP) and from 140 to $240 \mathrm{~mm} \mathrm{Hg}$ (PP). This suggests that in severe ARDS with localized lung injury, PP is likely to be more effective than PEEP, whereas those with diffuse injury may receive additional benefit from a further trial of increasing PEEP.

Various forms of recruitment maneuvers have been tested with PP, including periodic sighs, ${ }^{173}$ extended high-pressure post-inspiratory pauses, ${ }^{175}$ brief periods of either pressure control ventilation with super-PEEP, ${ }^{124}$ or high-level CPAP. ${ }^{174}$ Using spiral CT imaging, Galiatsou et al ${ }^{124}$ compared the impact of PP on augmenting a recruitment maneuver done in SP. In agreement with the previous studies on PP and PEEP, ${ }^{91}$ Galiatsou et al ${ }^{124}$ reported that both PP and recruitment maneuvers have an additive effect on improving oxygenation. However, in contrast to the findings of Gainnier et al, ${ }^{91} \mathrm{PP}$ was most effective in augmenting a recruitment maneuver in subjects with lobar infiltrates rather than those with diffuse infiltrates. Galiatsou et al ${ }^{124}$ found that a recruitment maneuver followed by PP improved lung aeration and reduced the risk of VILI. PP was more effective than a recruitment maneuver performed in $\mathrm{SP}$ in recruiting non-aerated dorsal lung and reversed overinflation of the ventral lung.

Comparing a recruitment maneuver done in SP with those done at 1 and $6 \mathrm{~h}$ after PP, Rival et al ${ }^{175}$ reported that the response to combining a recruitment maneuver with PP was more pronounced in subjects with ARDS $_{\mathrm{p}}$. The $\mathrm{P}_{\mathrm{aO}} / \mathrm{F}_{\mathrm{IO}_{2}}$ increased from 115 to $128 \mathrm{~mm} \mathrm{Hg}$ after the first recruitment maneuver in $\mathrm{SP}$ and increased to $230 \mathrm{~mm} \mathrm{Hg}$ after the final recruitment maneuver in PP. In ARDS $_{\text {exp }}$, $\mathrm{P}_{\mathrm{aO}_{2}} / \mathrm{F}_{\mathrm{IO}_{2}}$ increased from 102 to $107 \mathrm{~mm} \mathrm{Hg}$ after the recruitment maneuver in SP to $154 \mathrm{~mm} \mathrm{Hg}$ after the final recruitment maneuver in PP. Mean $\mathrm{P}_{\mathrm{aCO}_{2}}$ also decreased by $2-4 \mathrm{~mm} \mathrm{Hg}$ after each recruitment maneuver with a total decrease of approximately $7 \mathrm{~mm} \mathrm{Hg}$ from baseline to the final recruitment maneuver in PP. Most relevant was the fact that oxygenation improvements following a recruitment maneuver were transitory when done in SP but were sustained in PP.

In early $\mathrm{ARDS}_{\text {exp }}$, Oczenski et al ${ }^{174}$ found greater improvement in $\mathrm{P}_{\mathrm{aO}} / \mathrm{F}_{\mathrm{IO}_{2}}(60 \%)$ following a recruitment maneuver when analyzing only those subjects who were also responsive to PP. In these subjects, mean $\mathrm{P}_{\mathrm{aO}_{2}} / \mathrm{F}_{\mathrm{IO}_{2}}$ improved from $147 \mathrm{~mm} \mathrm{Hg}$ in SP to $225 \mathrm{~mm} \mathrm{Hg}$ after $6 \mathrm{~h}$ in PP and then increased to $368 \mathrm{~mm} \mathrm{Hg}$ just after the recruitment maneuver, an improvement that was sustained over $3 \mathrm{~h}$ in PP. Both $\mathrm{P}_{\mathrm{aCO}_{2}}$ and $\mathrm{C}_{\mathrm{RS}}$ also improved over $3 \mathrm{~h}$ 
following the recruitment maneuver in PP. In another study of early ARDS, Pelosi et al ${ }^{173}$ reported that adding sigh breaths to PP in order to achieve plateau pressures (Pplat) of $45 \mathrm{~cm} \mathrm{H}_{2} \mathrm{O}$ increased mean $\mathrm{P}_{\mathrm{aO}_{2}}$ more than sighs used in SP $(37 \pm 17 \mathrm{~mm} \mathrm{Hg}$ vs $16 \pm 11 \mathrm{~mm} \mathrm{Hg}$, respectively). Sighs increased EELV by $17 \%$ and decreased lung elastance by $17 \%$ when applied in PP but had only a minor impact when applied during SP. Moreover, the combination of sigh breaths and PP increased EELV over baseline measurements in SP by 35\%.

To date, only one RCT has reported the impact of combining a recruitment maneuver with PP on outcomes. In a recent study of 116 subjects with severe ARDS, Zhou et al ${ }^{176}$ reported decreased 28 -d mortality, duration of mechanical ventilation, and ICU stay in those managed with a recruitment maneuver and PP compared with controls. Unfortunately, only the study abstract is available in English, so that a thorough examination of the methodology and results is not currently available. In summary, a limited number of observational studies using various methods for alveolar recruitment consistently demonstrate that incorporating a recruitment maneuver with PP enhances oxygenation and should be considered when PP itself does not improve oxygenation.

\section{Inhaled Vasodilators}

Inhaled vasodilators, such as nitric oxide (INO), aerosolized prostacyclin, or alprostadil, are used to improve oxygenation in severe ARDS. ${ }^{177}$ These agents work as selective vasodilators enhancing perfusion of ventilated alveoli and thus improving $\mathrm{V}_{\mathrm{A}} / \mathrm{Q}$. Six observational studies involving 85 subjects examined the combined effects of INO and PP on gas exchange and hemodynamics in ARDS. ${ }^{178-182}$ In 5 of these studies, the combined therapies had an additive effect in improving oxygenation in subjects with early, severe ARDS of various etiologies. For example, mean $\mathrm{P}_{\mathrm{aO}_{2}}$ or $\mathrm{P}_{\mathrm{aO}} / \mathrm{F}_{\mathrm{IO}_{2}}$ increased an average of $29 \%$ with INO and $47 \%$ with PP alone, but when used together, oxygenation improved by an average of 88\%.25,179-182 Furthermore, combining these therapies substantially increased the prevalence of responders over either therapy alone from $54 \%$ (INO) and $76 \%$ (PP) to $92 \%$ for both. ${ }^{25,179,180,182}$

Some studies found that PP modestly enhanced the effects of INO in reducing pulmonary vascular resistance ${ }^{25}$ or mean pulmonary arterial pressure, ${ }^{182}$ whereas others did not. ${ }^{179-181}$ An important caveat in interpreting these studies is not only the small number of subjects enrolled $(n=14)$ but also the fact that both the INO dosage tested (1-13 ppm) and PP time ( $30 \mathrm{~min}$ to $6 \mathrm{~h}$ ) varied considerably. Although combining these therapies further enhances oxygenation and responder rate, the optimal combination of dose and timing remains unknown.
Investigation of bundled therapy for severe ARDS is in its nascent stage, and the potential impact on patient outcomes is unknown. However, several meta-analyses of therapeutic trials involving lung-protective ventilation in conjunction with $\mathrm{PP},{ }^{13}$ higher PEEP, ${ }^{183}$ neuromuscular blocking agent, ${ }^{184}$ and recruitment maneuvers ${ }^{185}$ suggest that these individual therapies improve outcomes in the most severe cohort of ARDS subjects. Since 2006, we have instituted a bundled approach using lung-protective ventilation with PP, aerosolized prostacyclin, and a variation of a previously described recruitment maneuver (pressure control ventilation with super-PEEP) ${ }^{186}$ in dire circumstances of refractory ARDS. Two cases of this technique are summarized for illustrative purposes (Figs. 6 and 7).

We have only found it necessary to utilize these extraordinary measures infrequently under immanently lifethreatening scenarios, wherein gas exchange could not be stabilized despite maximal therapies in SP. In general, the common features of these cases have been severe ARDS complicated by unusually low $\mathrm{C}_{\mathrm{CW}}$ from morbid obesity, abdominal compartment syndrome, or severe anasarca. Our experience has been similar to that described by Barbas et $\mathrm{al}^{186}$ in that a sustained recruitment maneuver in PP over several hours sometimes is necessary to stabilize gas exchange. Performing a recruitment maneuver in PP is preferable because the decreased $\mathrm{C}_{\mathrm{CW}}$ and more equal distribution of pleural pressure gradients reduce lung stress and the likelihood of barotrauma. However, it should be emphasized that in most cases of severe ARDS, we have found that PEEP levels between 16 and $24 \mathrm{~cm} \mathrm{H}_{2} \mathrm{O}$ in PP are sufficient to stabilize gas exchange.

\section{Extracorporeal Membrane Oxygenation}

Recently, PP has been used as an adjunctive therapy with extracorporeal membrane oxygenation (ECMO) in patients with severe ARDS ${ }^{187-194}$ All studies were retrospective in nature and consisted of case reports or case series. PP was used because of severe hypoxemia despite maximal ECMO and/or ventilatory support (eg, PEEP $=20 \mathrm{~cm} \mathrm{H}_{2} \mathrm{O}$ ), an inability to wean from ECMO, or an inability to treat atelectasis. PP typically was initiated 8-10 d into the course of ARDS. ${ }^{189-191}$ As in other studies, PP improved oxygenation that was sustained when subjects were returned to SP. In one case, PP induced pronounced secretion drainage with marked improvement in pulmonary function that expedited weaning from ECMO. ${ }^{189}$

The duration of PP sessions varied widely from 4 to $24 \mathrm{~h}$. Sometimes, a modified PP maneuver of $135^{\circ}$ was used to protect the intravascular catheter from compression or dislodgement. ${ }^{187,194}$ No catheter dislocations occurred during the turning procedures. Two additional retrospective studies of subjects with presumed ARDS who 


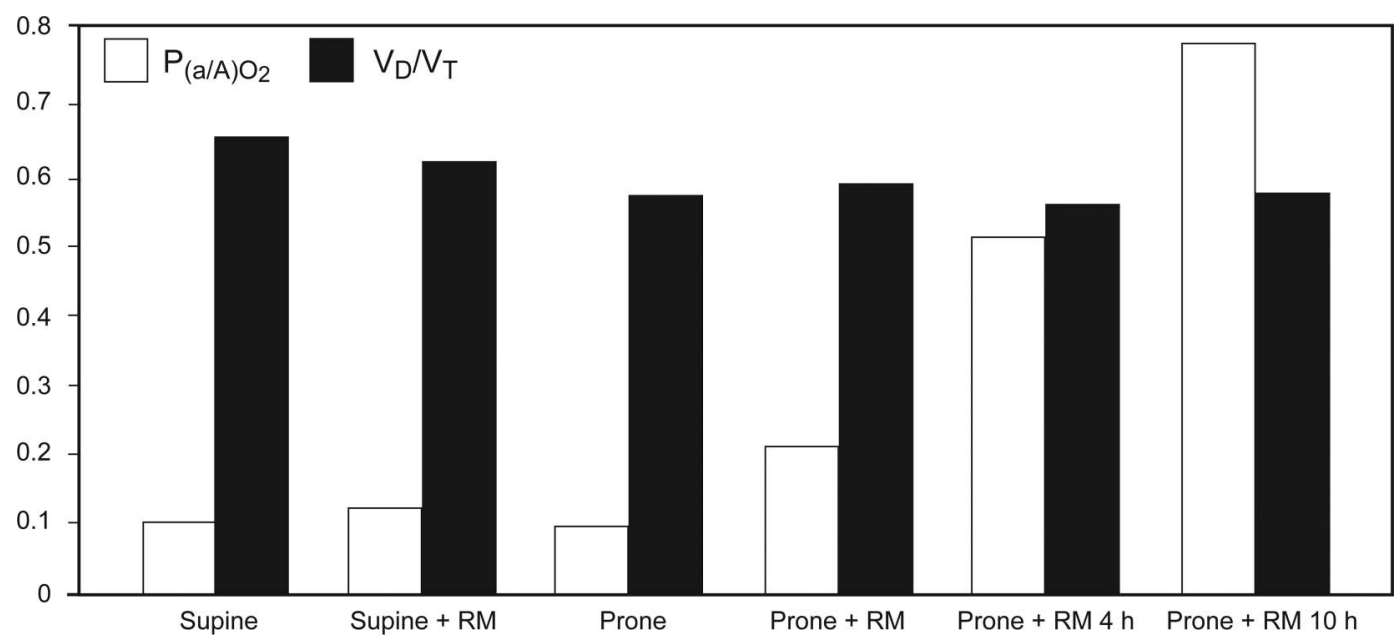

Fig. 6. A 39 -y-old obese male (body mass index of $32.2 \mathrm{~kg} / \mathrm{m}^{2}$ ) with aspiration-induced ARDS developed hypotension on ARDS day 9 and suffered lobar collapse. Despite an $\mathrm{F}_{\mathrm{IO}_{2}}$ of 1 , PEEP of $14 \mathrm{~cm} \mathrm{H} \mathrm{H}_{2} \mathrm{O}$, and the use of paralytics and maximal aerosolized prostacyclin (50 $\mathrm{ng} / \mathrm{kg} / \mathrm{min}$ ), the $\mathrm{P}_{\mathrm{aO}}$ was $56 \mathrm{~mm} \mathrm{Hg}$ and increased to only $63 \mathrm{~mm} \mathrm{Hg}$ following a recruitment maneuver (RM) using pressure control ventilation of $45 \mathrm{~cm} \mathrm{H} \mathrm{H}_{2} \mathrm{O}$ and PEEP of $25 \mathrm{~cm} \mathrm{H} \mathrm{H}_{2} \mathrm{O}$ for $3 \mathrm{~min}$. Although $\mathrm{P}_{\mathrm{aO}_{2}}$ improved minimally, physiologic dead-space ventilation $\left(\mathrm{V}_{\mathrm{D}} / \mathrm{V}_{\mathrm{T}}\right)$ decreased from 0.64 to 0.60 , suggesting lung recruitment. Once placed prone, the $\mathrm{P}_{\mathrm{aO}_{2}}$ acutely deteriorated to $49 \mathrm{~mm} \mathrm{Hg}$. In contrast, $V_{\mathrm{D}} / \mathrm{V}_{\mathrm{T}}$ continued to improve (0.55). At this point, the patient underwent a slow, step-wise recruitment maneuver using a fixed driving pressure of $20 \mathrm{~cm} \mathrm{H} \mathrm{H}_{2} \mathrm{O}$ as PEEP was increased in steps of 2-3 $\mathrm{cm} \mathrm{H}_{2} \mathrm{O}$ over 30 min to $30 \mathrm{~cm} \mathrm{H}_{2} \mathrm{O}$ with a plateau pressure of $50 \mathrm{~cm} \mathrm{H}_{2} \mathrm{O}$. Thirty min later, the $\mathrm{P}_{\mathrm{aO}}$ increased to $128 \mathrm{~mm} \mathrm{Hg}$. At 4 and $10 \mathrm{~h}$, the $\mathrm{P}_{\mathrm{aO}_{2}} / \mathrm{F}_{\mathrm{IO}_{2}}$ increased to $>300$ and $>500 \mathrm{~mm} \mathrm{Hg}$, respectively. The initial prone session was maintained for $16 \mathrm{~h}$. To facilitate visualization of the corresponding changes in oxygenation and $V_{\mathrm{D}} / \mathrm{V}_{\mathrm{T}}$, the ratio of arterial to alveolar oxygen tension $\mathrm{P}_{(\mathrm{a} / \mathrm{A}) \mathrm{O}_{2}}$ is used. For reference, a $\mathrm{P}_{\mathrm{aO}_{2}} / \mathrm{F}_{\mathrm{IO}_{2}}<100 \mathrm{~mm} \mathrm{Hg}$ corresponds to a ratio of arterial to alveolar oxygen tension of $<0.15$, whereas a normal value would reach 0.85 . Oxygenation improvements were sustained after returning to supine position. The patient was successfully extubated $18 \mathrm{~d}$ later and subsequently discharged alive from the hospital.

underwent PP during ECMO192,193 or continuous renalreplacement therapy 193 also reported no intravascular catheter-related or pump-related complications associated with PP. Because both internal jugular and femoral catheter sites were used, catheter location does not appear to influence potential risk. Despite the fact that only 51 subjects were observed in these studies, it suggests that neither ECMO nor the need for continuous renal-replacement therapy should be considered an absolute contraindication for PP in patients with severe ARDS.

\section{Practical Considerations: Indications, PEEP Strategy, Deescalating Therapy}

Several important practical issues regarding PP are when, how, and in whom this therapy should be considered in patients with ARDS. Based on the results of the PROSEVA study as well as some meta-analyses, PP should be used early $(\leq 72 \mathrm{~h})$ in the course of moderately severe $\left(\mathrm{P}_{\mathrm{aO}_{2}} / \mathrm{F}_{\mathrm{IO}_{2}} \leq 150 \mathrm{~mm} \mathrm{Hg}\right)$ or severe ARDS $\left(\mathrm{P}_{\mathrm{aO}_{2}} / \mathrm{F}_{\mathrm{IO}_{2}}\right.$ $<100 \mathrm{~mm} \mathrm{Hg}$ ) using the recent Berlin definition. ${ }^{195} \mathrm{How}-$ ever, this leaves open to debate whether the $\mathrm{P}_{\mathrm{aO}} / \mathrm{F}_{\mathrm{IO}_{2}}$ criteria used for initiating PP should also take into account both the amount of PEEP and $\mathrm{F}_{\mathrm{IO}_{2}}$ as well as whether a right heart-protective ventilation strategy is favored.

Several lines of evidence suggest that before considering PP, patients should first be given a trial of high PEEP (eg, 16-20 $\mathrm{cm} \mathrm{H}_{2} \mathrm{O}$ ). Using CT scan imaging, it is estimated that the pressure necessary to overcome both the superimposed hydrostatic pressure compressing the lung and the elastic recoil of the chest wall requires PEEP levels between 16 and $18 \mathrm{~cm} \mathrm{H}_{2} \mathrm{O} .{ }^{196} \mathrm{~A}$ review of studies examining the lower inflection point as a guide to setting PEEP level in early ARDS also suggests that a substantial proportion of ARDS patients require a PEEP level between 13 and $20 \mathrm{~cm} \mathrm{H}_{2} \mathrm{O}$ (assuming that $3 \mathrm{~cm} \mathrm{H}_{2} \mathrm{O}$ is added to the measured lower inflection point). ${ }^{197}$ If an initial trial of relatively high PEEP cannot stabilize oxygenation at a clinically nontoxic $\mathrm{F}_{\mathrm{IO}_{2}}(\mathrm{eg}, 0.60)$ within a reasonable amount of time (eg, 4-12 h), then PP should be strongly considered. This suggestion is based purely upon clinical experience that many patients with ARDS show a rapid and impressive improvement in oxygenation with just the application of PEEP in this range.

In contrast, there is a persuasive body of evidence summarized earlier in this review suggesting that PP should be used in lieu of higher PEEP in order to recruit and stabilize the lungs and prevent cor pulmonale in patients with severe ARDS (50\% of whom develop the complication). ${ }^{147}$ Higher levels of PEEP necessitate tolerance of a higher Pplat to maintain a reasonable level of alveolar ventilation and avoid acidosis that exacerbates pulmonary hypertension and right heart strain in ARDS. ${ }^{198}$ Moreover, despite the use of lung-protective ventilation, even moderate PEEP 


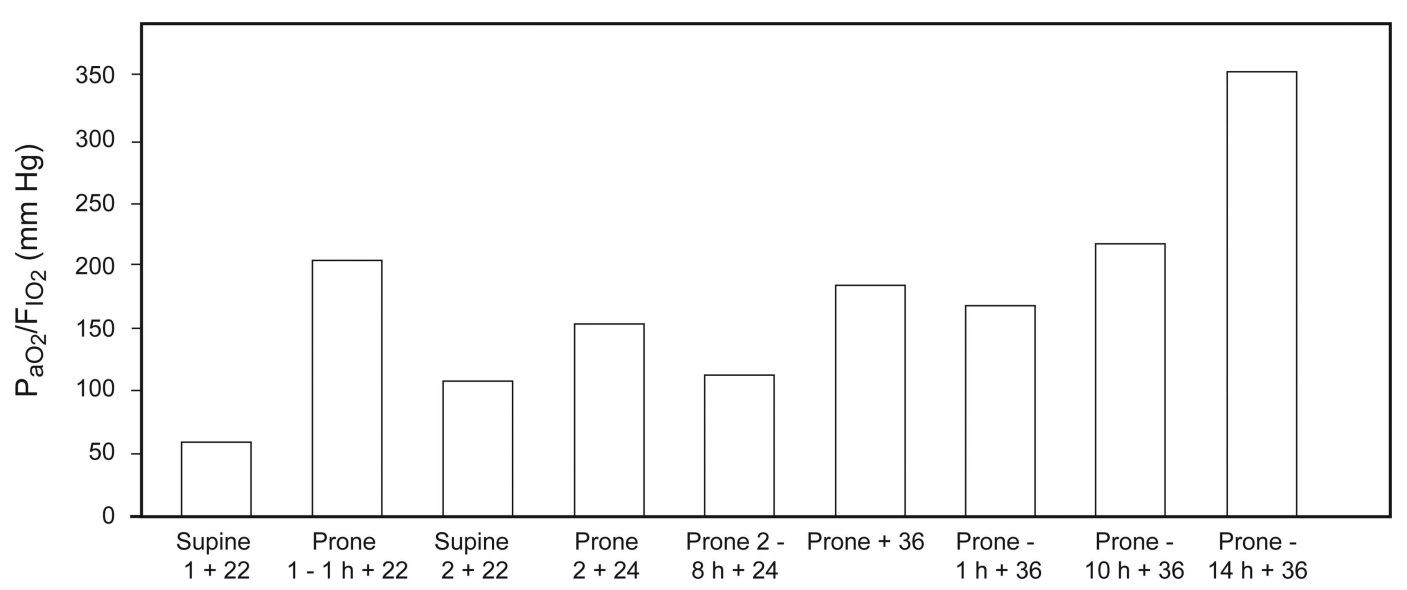

Fig. 7. A 39-y-old pregnant female (body mass index of $36.2 \mathrm{~kg} / \mathrm{m}^{2}$ ) in her third trimester who developed ARDS secondary to H1N1 influenza pneumonia underwent emergency cesarean section in the ICU for severe hypoxemia $\left(\mathrm{S}_{\mathrm{pO}_{2}}\right.$ of $\left.74 \%\right)$ with loss of fetal heart rate. She was successfully managed in SP on PEEP of $16 \mathrm{~cm} \mathrm{H}_{2} \mathrm{O}$ until ARDS d 3, when her $\mathrm{P}_{\mathrm{aO}_{2}}$ fell to $48 \mathrm{~mm} \mathrm{Hg}$ on an $\mathrm{F}_{\mathrm{IO}_{2}}$ of 1 and PEEP of $22 \mathrm{~cm} \mathrm{H} \mathrm{H}_{2} \mathrm{O}$ $(\mathrm{SP} 1+22)$. An hour after her first prone session, her oxygenation improved substantially $(\mathrm{PP}-1 \mathrm{H}+22)$ until she was returned to supine $5 \mathrm{~h}$ later for wound care. Her oxygenation again deteriorated despite an $\mathrm{F}_{\mathrm{IO}_{2}}$ of 1 and PEEP of $22 \mathrm{~cm} \mathrm{H}_{2} \mathrm{O}(\mathrm{SP} 2+22)$. Returning her to prone resulted in transient improvement in oxygenation over the following $16 \mathrm{~h}$ despite increasing PEEP to $24 \mathrm{~cm} \mathrm{H}_{2} \mathrm{O}(\mathrm{PP} 2+24$; $\mathrm{PP}-2-8 \mathrm{H}+24)$. A prolonged super-PEEP recruitment maneuver as described previously (Fig 6) was implemented with a plateau pressure (Pplat) of $55 \mathrm{~cm} \mathrm{H} \mathrm{H}_{2} \mathrm{O}$, PEEP of $36 \mathrm{~cm} \mathrm{H}_{2} \mathrm{O}, \mathrm{V}_{\mathrm{T}}$ of $7-8 \mathrm{~mL} / \mathrm{kg}$, and breathing frequency of 30 breaths/min. Within 30 min, there was a marked improvement in $\mathrm{P}_{\mathrm{aO}_{2}} / \mathrm{F}_{\mathrm{IO}_{2}}(\mathrm{PP}+36)$ that slowly increased to $>200 \mathrm{~mm} \mathrm{Hg}$ at $10 \mathrm{~h}(\mathrm{PP}-10+36)$ and $>300 \mathrm{~mm} \mathrm{Hg} 4 \mathrm{~h}$ later $(\mathrm{PP}-14 \mathrm{H}+36)$. Despite continued episodes of derecruitment when turned to supine, the patient was managed successfully in prone at lower levels of PEEP $\left(15 \mathrm{~cm} \mathrm{H} \mathrm{H}_{2} \mathrm{O}\right)$ and without the use of paralytics over the next several days. Unfortunately, $10 \mathrm{~d}$ later, the patient developed severe cor pulmonale secondary to a massive pulmonary embolus and died shortly thereafter.

levels (eg, $13 \mathrm{~cm} \mathrm{H}_{2} \mathrm{O}$ ) impair RV function, ${ }^{199}$ which is exacerbated further by the presence of acute respiratory acidosis. ${ }^{200}$ In a right heart-protective approach, the targets are a Pplat $<27 \mathrm{~cm} \mathrm{H}_{2} \mathrm{O}$ and an elastic driving pressure $\left(\mathrm{P}_{\text {plat }}-\mathrm{PEEP}\right)<17 \mathrm{~cm} \mathrm{H}_{2} \mathrm{O} .{ }^{147}$ This would necessitate restricting PEEP to approximately $10-12 \mathrm{~cm} \mathrm{H}_{2} \mathrm{O}$. Therefore, adhering to a right heart-protective ventilation strategy virtually necessitates incorporating PP into the management strategy for moderately severe and severe ARDS.

In clinical practice, deescalating PP therapy will largely be dictated by patient response, priorities related to oxygenation interpreted within the context of PEEP and $\mathrm{F}_{\mathrm{IO}_{2}}$ goals, and considerations of preventing VILI and cor pulmonale. Among the later RCTs that used PP sessions averaging $17-20 \mathrm{~h}$, the number of days PP was required to meet predetermined discontinuation criteria averaged 4,8 , and $10 \mathrm{~d}^{6,133,164}$ In the study by Voggenreiter et al, ${ }^{132} \mathrm{PP}$ sessions averaged $11 \mathrm{~h}$, and subjects required an average of $7 \mathrm{~d}$ before discontinuation.

Various criteria have been used to test discontinuation of PP that may explain the wide variability between studies in the required number of PP sessions. The PROSEVA study ${ }^{6}$ required a $\mathrm{P}_{\mathrm{aO}_{2}} / \mathrm{F}_{\mathrm{IO}_{2}}>150 \mathrm{~mm} \mathrm{Hg}$ on a $\mathrm{F}_{\mathrm{IO}_{2}} \leq 0.6$ and PEEP $\leq 10 \mathrm{~cm} \mathrm{H}_{2} \mathrm{O}$, which would translate to a $\mathrm{P}_{\mathrm{aO}_{2}}$ of $90 \mathrm{~mm} \mathrm{Hg}$. Fernandez et $\mathrm{al}^{119}$ appeared to have required a stable $\mathrm{P}_{\mathrm{aO}_{2}} / \mathrm{F}_{\mathrm{IO}_{2}} \geq 250 \mathrm{~mm} \mathrm{Hg}$ on a $\mathrm{F}_{\mathrm{IO}_{2}}$ of 0.5 and PEEP $\leq 8 \mathrm{~cm} \mathrm{H}_{2} \mathrm{O}$ for $12 \mathrm{~h}$ before attempting to discontinue PP. Similarly, Voggenreiter et al ${ }^{132}$ mandated a stable $\mathrm{P}_{\mathrm{aO}_{2}} / \mathrm{F}_{\mathrm{IO}_{2}} \geq 300 \mathrm{~mm} \mathrm{Hg}$ for $48 \mathrm{~h}$ in both PP and SP before discontinuing PP.

Currently, there is no way of discerning whether any particular criterion for discontinuing PP is optimal. Relying upon reversal of $\mathrm{P}_{\mathrm{aO}_{2}} / \mathrm{F}_{\mathrm{IO}_{2}}$ criteria for ARDS (ie, $\mathrm{P}_{\mathrm{aO}_{2}} / \mathrm{F}_{\mathrm{IO}_{2}}>300 \mathrm{mmHg}$ ) appears to be influenced by values used to signify full lung recruitment, which has been defined as achieving a value of $\mathrm{P}_{\mathrm{aO}_{2}}+\mathrm{P}_{\mathrm{aCO}_{2}}>400 \mathrm{~mm} \mathrm{Hg}$ ( $\pm 5 \%$ ) on an $\mathrm{F}_{\mathrm{IO}_{2}}$ of $1 .{ }^{191}$ However, in patients with ARDSp or in the subacute phase, there may be limited recruitment with PP, so that achieving $\mathrm{P}_{\mathrm{aO}_{2}} / \mathrm{F}_{\mathrm{IO}_{2}}>300$ may not be a realistic expectation. The obvious advantage of the PROSEVA criterion is that it allows an aggressive challenge to test discontinuation of PP when oxygenation is reasonably stable. This in turn may facilitate a reduction in the duration of mechanical ventilation (albeit indirectly) but may increase the risk of gas exchange instability. In contrast, requiring greater lung recruitment and stabilization before discontinuing PP may result in fewer incidences of hypoxemic relapses but may needlessly prolong the duration of mechanical ventilation.

\section{Manual Versus Automated PP}

Manual PP maneuvers are relatively easy to perform quickly with appropriate staffing. ${ }^{201}$ Therefore, defined roles are required for each clinician with a clear, detailed description of all preparatory and procedural steps that can 
be used during training of staff and during the actual procedure. This ensures that all patient care aspects are addressed, from preparation to turning, maintaining patients in PP, and their return to SP. It is preferable to design this in a checklist format readily available at the bedside. Such a checklist developed at San Francisco General Hospital is provided as a template (see the supplementary materials at http://www.rcjournal.com). Beds that provide automated PP are available and have the advantage of requiring fewer clinicians to accomplish the procedure and providing a faster ability to return patients to SP in case of emergencies.

PP generates pressure ulcers at a constant rate. ${ }^{166}$ Therefore, regardless of PP technique, proactive skin care is required with sufficient padding of pressure points. In the PROSEVA study, ${ }^{6}$ prior to PP, adhesive pads were placed on the forehead, chest, iliac crest, and knees to prevent skin erosions. Others have fashioned special head support devices for PP, ${ }^{202,203}$ one of which was found to significantly reduce both the incidence and area of skin ulcerations to the face during manual PP. ${ }^{202}$ Other suggestions to reduce the incidence and severity of pressure ulcerations can be found elsewhere. ${ }^{127}$

\section{Incorporating Continuous Rotational Therapy With PP}

Continuous rotational therapy has been used since the 1990s to improve oxygenation in ARDS. ${ }^{204,205}$ Continuous rotational therapy improves oxygenation compared with SP; the magnitude of improvement is comparable to PP. ${ }^{204}$ Two small studies have compared PP with continuous rotational therapy, ${ }^{206,207}$ Whereas both studies found similar improvements in $\mathrm{P}_{\mathrm{aO}_{2}} / \mathrm{F}_{\mathrm{IO}_{2}}$, the oxygen responder rate was markedly lower in continuous rotational therapy compared with PP in one study (50\% vs $83 \%$, respectively) ${ }^{207}$ and essentially equivalent in the other study (69 and 68\%, respectively). ${ }^{206}$ However, the most detailed physiologic study ${ }^{205}$ of continuous rotational therapy found large improvements in $\mathrm{P}_{\mathrm{aO}_{2}} / \mathrm{F}_{\mathrm{IO}_{2}}$ only in cases of mild to moderate ARDS (lung injury scores $\leq 2.5$ ) and did not appreciably improve oxygenation in severe or prolonged ARDS.

Hemodynamic instability requiring modification of continuous rotational therapy was reported in $21 \%$ of subjects compared with no instability in subjects assigned to PP. ${ }^{206}$ Previously, Jolliet et al ${ }^{85}$ reported transient hemodynamic instability during the turn to PP when the subjects were briefly in the lateral decubitus position. The maximal sideto-side rotation used during continuous rotational therapy in this study was $124^{\circ}$ over a $4-m i n$ cycle. ${ }^{206} \mathrm{~A}$ resource publication for the Rotoprone bed (KCI Therapeutic Support Systems, San Antonio TX), ${ }^{208}$ recommends continuous rotational therapy between $40^{\circ}$ and $62^{\circ}$ on each side with a 1-min pause at the apex of the lateral decubitus position. PP-continuous rotational therapy is recommended to occur in cycles of $3.25 \mathrm{~h}$ followed by $.75 \mathrm{~h}$ in SP. It has been suggested that PP-continuous rotational therapy with PP with Rotoprone beds may increase the incidence of hypotension because of increased sedation requirements for tolerating continuous rotational therapy. ${ }^{57}$

The purported benefit of incorporating continuous rotational therapy with PP is to ameliorate skin breakdown. ${ }^{208}$ However, the incidence of new pressure ulcers and skin tears reported by Bajwa et $\mathrm{al}^{99}$ was high and similar to that in other PP studies reviewed here. Moreover, radical and continuous posture changes inherent to continuous rotational therapy cannot be considered lung-protective. Rather it is potentially VILI-enhancing through the perpetual creation of large pleural pressure gradients throughout the lung. The transverse chest diameter is 3 times greater than the sternovertebral height, ${ }^{56}$ which is between 12 and $25 \mathrm{~cm}$ in adults. ${ }^{209}$ This suggests that an unusually broad range of pleural pressure gradients and superimposed hydrostatic pressures (and therefore alveolar strain-stress relationships) may exist throughout the lungs when patients are placed at $62^{\circ}$ in the lateral decubitus position. This becomes a particularly important factor when high-level PEEP is required.

Recruitment requires both pressure and time and is more likely to produce benefits sooner when done in the prone decubitus position. Moreover, it is impossible to know whether continuous rotational therapy causes more overinflation than recruitment in patients who have lobar, patchy, or diffuse lung injury. Furthermore, in early ARDS (when alveolar edema is prevalent), dramatic side-to-side position changes increase the risk of spreading pro-inflammatory mediators or bacteria to noninjured areas of the lungs. ${ }^{210}$ Continuous rotational therapy may not be effective in improving oxygenation in severe ARDS, may enhance the spread of inflammation, and may also aggravate VILI. Therefore, continuous rotational therapy should either be avoided during PP or used cautiously with mild degrees of rotation.

\section{Summary}

In summary, the primary effect of PP on chest mechanics and gas exchange physiology is to cause more even $\mathrm{P}_{\mathrm{PL}}$ distribution that in turn results in more uniform alveolar size throughout the lung. This effect is complemented by the corresponding reductions in the compressive effects of both the heart and the abdomen. In contrast, pulmonary perfusion is relatively unaffected by positional changes, so that pulmonary perfusion remains preferentially distributed to the dorsal lung regions in PP. The overall effect on gas exchange is increased $V_{A} / Q$ and, in the presence of experimental or clinical ARDS, facilitation of lung recruit- 


\section{Prone Position In ARDS}

ment by lowering the threshold for recruiting collapsed airways and alveoli.

The preponderance of evidence demonstrates that most patients with ARDS $(\geq 70 \%)$ managed in PP have improved oxygenation regardless of etiology or timing of initiation. It appears that early intervention with PP is more likely to be effective, but improved oxygenation frequently has been reported when PP is used during the subacute phase. The time course for maximal improvement in oxygenation is variable from several hours to several days. However, most studies suggest that PP sessions should be sustained for no less than $10-12 \mathrm{~h}$ and ideally for 16-20 h. The impact of PP on improving alveolar ventilation is less consistent and may be explained by recent evidence that there are both $\mathrm{P}_{\mathrm{aO}_{2}}$ and $\mathrm{P}_{\mathrm{aCO}_{2}}$ responders to $\mathrm{PP}$, reflecting the extent and distribution of lung injury. That many studies reported no impact on $\mathrm{P}_{\mathrm{aCO}}$ may be due to a balancing of these 2 subgroups.

Meta-analyses of RCTs demonstrate that PP provides a survival advantage in subjects with relatively severe ARDS $\left(\mathrm{P}_{\mathrm{aO}_{2}} / \mathrm{F}_{\mathrm{IO}_{2}}<150 \mathrm{~mm} \mathrm{Hg}\right)$. This reflects the impact of PP on either delaying the onset or reducing the severity VILI. Reduction in hypoxic pulmonary vasoconstriction and vascular resistance also may reduce the likelihood of developing cor pulmonale that is believed to increase mortality risk in ARDS. Combining other adjunctive therapies with PP appears to have an additive effect in improving oxygenation, thus providing clinicians with an array of strategies to stabilize gas exchange.

\section{REFERENCES}

1. Mellins RB. Pulmonary physiotherapy in the pediatric age group. Am Rev Respir Dis 1974;110(6):137-142.

2. Piehl MA, Brown RS. Use of extreme position changes in acute respiratory failure. Crit Care Med 1976;4(1):13-14.

3. Douglas WW, Rehder K, Beynen FM, Sessler AD, Marsh HM. Improved oxygenation in patients with acute respiratory failure: the prone position. Am Rev Respir Dis 1977;115(4):559-566.

4. Froese AB, Bryan AC. Effects of anesthesia and paralysis on diaphragmatic mechanics in man. Anesthesiology 1974;41(3):242-255.

5. Bryan AC. Comments of a devil's advocate. Am Rev Respir Dis 1974;110(6 Pt 2):143-144.

6. Guérin C, Reignier J, Richard JC, Beuret P, Gacouin A, Boulain T, et al. PROSEVA Study Group: prone positioning in severe acute respiratory distress syndrome. N Engl J Med 2013;368(23):21592168.

7. Abroug F, Ouanes-Besbes L, Elatrous S, Brochard L. The effect of prone positioning in acute respiratory distress syndrome or acute lung injury: a meta-analysis: areas of uncertainty and recommendations for research. Intensive Care Med 2008;34(6):1002-1011.

8. Alsaghir AH, Martin CM. Effect of prone positioning in patients with acute respiratory distress syndrome: a meta-analysis. Crit Care Med 2008;36(2):603-609.

9. Lee JM, Bae W, Lee YJ, Cho YJ. The efficacy and safety of prone positional ventilation in acute respiratory distress syndrome: updated study-level meta-analysis of 11 randomized controlled trials. Crit Care Med 2014;42(5):1252-1262.
10. Hu SL, He HL, Pan C, Liu AR, Liu SQ, Liu L, et al. The effect of prone positioning on mortality in patients with acute respiratory distress syndrome: a meta-analysis of randomized controlled trials. Crit Care 2014;18(3):R109.

11. Beitler JR, Shaefi S, Montesi SB, Devlin A, Loring SH, Talmor D, Malhotra A. Prone positioning reduces mortality from acute respiratory distress syndrome in the low tidal volume era: a meta-analysis. Intensive Care Med 2014;40(3):332-341.

12. Gattinoni L, Carlesso E, Taccone P, Polli F, Guérin C, Mancebo J. Prone positioning improves survival in severe ARDS: a pathophysiologic review and individual patient meta-analysis. Minerva Anestesiol 2010;76(6):448-454.

13. Sud S, Friedrich JO, Taccone P, Polli F, Adhikari NKJ, Latini R, et al. Prone ventilation reduces mortality in patients with acute respiratory failure and severe hypoxemia: systematic review and meta-analysis. Intensive Care Med 2010;36(4):585-599.

14. NHLBI Acute Respiratory Distress Syndrome Network. Ventilation with lower tidal volumes as a compared with traditional tidal volumes for acute respiratory distress syndrome. N Engl J Med 2000;342(18):1301-1308.

15. Hedenstierna G, Strandberg A, Brismar B, Lundquist H, Svensson L, Tokics L. Functional residual capacity, thoracoabdominal dimensions, and central blood volume during general anesthesia with muscle paralysis and mechanical ventilation. Anesthesiology 1985; 62(3):247-254.

16. West JB. Respiratory physiology: the essentials. 9th edition. Philadelphia: Lippincott Williams \& Wilkins; 2012:105.

17. Agostoni E. Mechanics of the pleural space. Physiol Rev 1972; 52(1):57-128.

18. Froese AB. Gravity, the belly and the diaphragm: you can't ignore physics. Anesthesiology 2006;104(1):193-196.

19. Agostoni E, D'Angelo E, Bonanni MV. The effect of the abdomen on the vertical gradient of pleural surface pressure. Respir Physiol 1970;8(3):332-346.

20. De Keulenaer BL, De Waele JJ, Powell B, Malbrain MLNG. What is normal intra-abdominal pressure and how is it affected by psotioning, body mass and positive end-expiratory pressure? Intensive Care Med 2009;35(6):969-976.

21. Malbrain MLNG. Abdominal pressure in the critically ill: measurement and clinical relevance. Intensive Care Med 1999;25(12):14531458.

22. Pelosi P, Croci M, Calappi E, Mulazzi D, Cerisara M, Vercesi P, Vicardi P, Gattinoni L. Prone positioning improves pulmonary function in obese patients during general anesthesia. Anesth Analg 1996; 83(3):578-583.

23. Pelosi P, Croci M, Calappi E, Cerisara M, Mulazzi D, Vicardi P, Gattinoni L. The prone positioning during general anesthesia minimally affects respiratory mechanics while improving functional residual capacity and increasing oxygen tension. Anesth Analg 1995; 80(5):955-960.

24. Fridrich P, Krafft P, Hochleuthner H, Mauritz W. The effects of long-term prone positioning in patients with trauma-induced adult respiratory distress syndrome. Anesth Analg 1996;83(6):1206-1211.

25. Johannigman JA, Davis K Jr, Miller SL, Campbell RS, Luchette FA, Frame SB, Branson RD. Prone positioning and inhaled nitric oxide: syngergistic therapies for acute respiratory distress syndrome. J Trauma 2001;50(4):589-595; discussion 595-596.

26. Lim CM, Kim EK, Lee JS, Shim TS, Lee SD, Koh Y, et al. Comparison of the response to the prone position between pulmonary and extrapulmonary acute respiratory distress syndrome. Intensive Care Med 2001;27(3):477-485.

27. Stocker R, Neff T, Stein S, Ecknauer E, Trentz O, Russi E. Prone positioning and low-volume pressure-limited ventilation improve 


\section{PRONe Position IN ARDS}

survival in patients with severe ARDS. Chest 1997;111(4):10081017.

28. Jozwiak M, Teboul JL, Anguel N, Persichini R, Silva S, Chemla D, et al. Beneficial hemodynamic effects of prone positioning in patients with acute respiratory distress syndrome. Am J Respir Crit Care Med 2013;188(12):1428-1433.

29. Johannigman JA, Davis K Jr, Miller SL, Campbell RS, Luchette FA, Frame SB, Branson RD. Prone positioning for acute respiratory distress syndrome in the surgical intensive care unit: Who when and how long? Surgery 2000;128(4):708-716.

30. Offner PJ, Haenel JB, Moore EE, Biffl WL, Franciose RJ, Burch JM. Complications of prone ventilation in patients with multisystem trauma with fulminant acute respiratory distress syndrome. J Trauma 2000;48(2):224-228.

31. Blanch L, Mancebo J, Perez M, Martinez M, Mas A, Betbese AJ, et. al. Short-term effects of prone position in critically ill patients with acute respiratory distress syndrome. Intensive Care Med 1997; 23(10):1033-1039.

32. Servillo G, Roupie E, De Robertis E, Rossano F, Brochard L, Lemaire F, Tufano R. Effect of ventilation in the decubitus position on respiratory mechanics in adult respiratory distress syndrome. Intensive Care Med 1997;23(12):1219-1224.

33. Voggenreiter G, Neudeck F, Aufmkolk M, Fassbinder J, Hirche H, Obertacke U, Schmit-Neuerburg KP. Intermittent prone positioning in the treatment of severe and moderate post traumatic lung injury. Crit Care Med 1999;27(11):2375-2382.

34. Kallet RH, Katz JA. Respiratory system mechanics in acute respiratory distress syndrome. Respir Care Clin N Am 2003;9(3):297319.

35. Lee DL, Chiang HT, Lin SL, Ger LP, Kun MH, Huang YC. Proneposition ventilation induces sustained improvement in oxygenation in patients with acute respiratory distress syndrome who have a large shunt. Crit Care Med 2002;30(7):1446-1452.

36. Pelosi P, Tubiolo D, Mascheroni D, Vicardi P, Crotti S, Valenza F, Gattinoni L. Effects of the prone position on respiratory mechanics and gas exchange during acute lung injury. Am J Respir Crit Care Med 1998;157(2):387-393.

37. Guerin C, Badet M, Rosselli S, Heyer L, Sab JM, Langevin B, et al. Effects of prone position on alveolar recruitment and oxygenation in acute lung injury. Intensive Care Med 1999;25(11):1222-1230.

38. Grimby G, Hedenstierna G, Löfström B. Chest wall mechanics during artificial ventilation. J Appl Physiol 1975;38(4):576-580.

39. Palmon SC, Kirsch JR, Depper JA, Toung TJK. The effect of the prone position on pulmonary mechanics is frame-dependent. Anesth Analg 1998;87(5):1175-1180.

40. Albert RK, Leasa D, Sanderson M, Robertson HT, Hlastala MP. The prone position improves oxygenation and reduces shunt in oleic acid-induced acute lung injury. Am Rev Respir Dis 1987; 135(3):628-633

41. Chiumello D, Cressoni M, Racagni M, Landi L, Li Bassi G, Polli $\mathrm{F}$, et al. Effects of thoro-pelvic supports during prone positioning in patients with acute lung injury/acute respiratory distress syndrome: a physiologic study. Crit Care 2006;10(3):R87.

42. Vieillard-Baron A, Rabiller A, Chergui K, Peyrouset O, Page B, Beauchet A, Jardin F. Prone position improves mechanics and alveolar ventilation in acute respiratory distress syndrome. Intensive Care Med 2005;31(2):220-226.

43. Glenny RW, Robertson HT. Spatial distribution of ventilation and perfusion: mechanisms and regulation. Compr Physiol 2011;1(1): 375-395.

44. Hopkins SR, Henderson AC, Levin DL, Yamada K, Arai T, Buxton RB, Prisk GK. Vertical gradients in regional lung density and perfusion in the supine human lung: the Slinky effect. J Appl Physiol 2007;103(1):240-248
45. Kaneko K, Milic-Emili J, Dolovich MB, Dawson A, Bates DV. Regional distribution of ventilation and perfusion as a function of body position. J Appl Physiol 1966;21(3):767-777.

46. Bendixen HH, Hedley-Whyte J, Laver MB. Impaired oxygenation in surgical patients during general anesthesia with controlled ventilation. N Engl J Med 1963;269(19):991-996.

47. Pontoppidan H, Hedley-Whyte J, Bendixen HH, Laver MB, Radford EP Jr. Ventilation and oxygen requirements during prolonged artificial ventilation in patients with respiratory failure. $\mathrm{N}$ Engl J Med 1965;273(8):401-409.

48. Visick WD, Fairley HB, Hickey RF. The effects of tidal volume and end-expiratory pressure on pulmonary gas exchange during anesthesia. Anesthesiology 1973;39(3):285-290.

49. Albert RK, Hubmayr RD. The prone position eliminates compression of the lungs by the heart. Am J Respir Crit Care Med 2000; 161(5):1660-1665.

50. Gattinoni L, Pesenti A, Carlesso E. Body position changes redistribute lung computed tomographic density in patients with acute respiratory failure: impact and clinical fallout through the following 20 years. Intensive Care Med 2013;39(11):1909-1915.

51. Gattinoni L, Pelosi P, Vitale G, Pesenti A, D’Andrea L, Mascheroni D. Body position changes redistribute lung computed-tomographic density in patients with acute respiratory failure. Anesthesiology 1991;74(1):15-23.

52. Petersson J, Rohdin M, Sánchez-Crespo A, Nyrén S, Jacobsson H, Larsson SA, et al. Posture primarily affects lung tissue distribution with minor effect on blood flow and ventilation. Respir Physiol Neurobiol 2007;156(3):293-303.

53. Broccard A, Shapiro RS, Schmitz LL, Adams AB, Nahum A, Marini JJ. Prone positioning attenuates and redistributes ventilator-induced lung injury in dogs. Crit Care Med 2000;28(2):295-303.

54. Krayer S, Rehder K, Vettermann J, Didier EP, Ritman E. Position and motion of the human diaphragm during anesthesia-paralysis. Anesthesiology 1989;70(6):891-898.

55. Rehder K, Knopp TJ, Sessler AD. Regional intrapulmonary gas distribution in awake and anesthetized-paralyzed prone man. J Appl Physiol 1978;45(4):528-535.

56. Pappert D, Rossaint R, Slama K, Grüning T, Falke KJ. Influence of positioning on ventilation-perfusion relationships in severe adult respiratory distress syndrome. Chest 1994;106(5):1511-1516.

57. Benson AB, Albert RK. Prone positioning for acute respiratory distress syndrome. Clin Chest Med 2014;35(4):743-752.

58. Nyrén S, Mure M, Jacobsson H, Larsson SA, Lindahl SGE. Pulmonary perfusion is more uniform in the prone than in the supine position: scintigraphy in healthy humans. J Appl Physiol 1999; 86(4):1135-1141.

59. Nyrén S, Radell P, Lindahl SGE, Mure M, Petersson J, Larsson SA, et al. Lung ventilation and perfusion in prone and supine postures with reference to anesthetized and mechanically ventilated healthy volunteers. Anesthesiology 2010;112(3):682-687.

60. Glenny RW, Robertson HT. Determinants of pulmonary blood flow distribution. Compr Physiol 2011;1(1):39-59.

61. Rimeika D, Nyrén S, Wiklund NP, Koskela LR, Tørring A, Gustafsson LE, et al. Regulation of regional lung perfusion by nitric oxide. Am J Respir Crit Care Med 2004;170(4):450-455.

62. Hlastala MP, Glenny RW. Vascular structure determines pulmonary blood flow distribution. News Physiol Sci 1999;14:182-186.

63. Beck KC, Vettermann J, Rehder K. Gas exchange in dogs in the prone and supine positions. J Appl Physiol 1992;72(6):2292-2297.

64. Mure M, Domino KB, Lindahl SGE, Hlastala MP, Altemeier WA, Glenny RW. Regional ventilation-perfusion distribution is more uniform in the prone position. J Appl Physiol 2000;88(3):10761083. 


\section{PRONe Position IN ARDS}

65. Lamm WJE, Graham MM, Albert RK. Mechanism by which the prone position improves oxygenation in acute lung injury. Am $\mathrm{J}$ Respir Crit Care Med 1994;150(1):184-193.

66. Wiener CM, Kirk W, Albert RK. Prone position reverses gravitational distribution of perfusion in dog lungs with oleic acid-induced injury. J Appl Physiol 1990;68(4):1386-1392.

67. Mutoh T, Guest RJ, Lamm WJE, Albert RK. Prone position alters the effect of volume overload on regional pleural pressures and improves hypoxemia in pigs in vivo. Am Rev Respir Dis 1992; 146(2):300-306.

68. Mutoh T, Lamm WJE, Embree LJ, Hildebrandt J, Albert RK. Volume infusion produces abdominal distension, lung compression, and chest wall stiffening in pigs. J Appl Physiol 1992;72(2):575582.

69. Quintel M, Pelosi P, Caironi P, Meinhardt JP, Luecke T, Hermann $\mathrm{P}$, et al. An increase of abdominal pressure increases pulmonary edema in oleic acid-induced lung injury. Am J Respir Crit Care Med 2004;169(4):534-541.

70. Mure M, Glenny RW, Domino KB, Hlastala MP. Pulmonary gas exchange improves in the prone position with abdominal distension. Am J Respir Crit Care Med 1998;157(6):1785-1790.

71. Lamm WJE, Starr IR, Neradilek B, Polissar NL, Glenny RW, Hlastala MP. Hypoxic pulmonary vasoconstriction is heterogeneously distributed in the prone dog. Respir Physiol Neurobiol 2004;144(2):281-294

72. Hlastala MP, Lamm WJE, Karp A, Polissar NL, Starr IR, Glenny RW. Spacial distribution of hypoxic pulmonary vasoconstriction in the supine pig. J Appl Physiol 2004;96(5):1589-1599.

73. Starr IR, Lamm WJE, Neradilek B, Polissar N, Glenny RW, Hlastala MP. Regional hypoxic pulmonary vasoconstriction in prone pigs. J Appl Physiol 2005;99(1):363-370.

74. Hedenstierna G, White FC, Mazzone R, Wagner PD. Redistribution of pulmonary blood flow in the dog with PEEP ventilation. J Appl Physiol 1979;46(2):278-287.

75. Walther SM, Domino KB, Glenny RW, Hlastala MP. Positive endexpiratory pressure redistributes perfusion to dependent lung regions in supine but not in prone lambs. Crit Care Med 1999;27(1): 37-45.

76. Walther SM, Johansson MJ, Flatebø T, Nicolaysen A, Nicolaysen G. Marked differences between prone and supine sheep in effect of PEEP on perfusion distribution in zone II lung. J Appl Physiol 2005;99(3):909-914.

77. Richard JC, Decailliot F, Janier M, Annat G, Guérin C. Effects of positive end-expiratory pressure and body position on pulmonary blood flow redistribution in mechanically ventilated normal pigs. Chest 2002;122(3):998-1005.

78. Johansson MJ, Wiklund A, Flatebø T, Nicolaysen A, Nicolaysen G, Walther SM. Positive end-expiratory pressure affects regional distribution of ventilation differently in prone and supine sheep. Crit Care Med 2004;32(10):2039-2044.

79. Richard JC, Bregeon F, Costes N, Bars DLE, Tourvieille C, Lavenne $\mathrm{F}$, et al. Effects of prone position and positive end-expiratory pressure on lung perfusion and ventilation. Crit Care Med 2008;36(8): 2373-2380.

80. Langer M, Mascheroni D, Marcolin R, Gattinoni L. The prone position in ARDS patients: a clinical study. Chest 1988;94(1):103107.

81. Vollman KM, Bander JJ. Improved oxygenation utilizing a prone positioner with acute respiratory distress syndrome. Intensive Care Med 1996;22(10):1105-1111.

82. Chatte G, Sab JM, Dubois JM, Sirodot M, Gaussorgues P, Robert D. Prone position in mechanically ventilated patients with severe acute respiratory failure. Am J Respir Crit Care Med 1997;155(2): 473-478.
83. Mure M, Martling CR, Lindahl SGE. Dramatic effect on oxygenation in patients with severe acute lung insufficiency treated in the prone position. Crit Care Med 1997;25(9):1539-1544.

84. Flaatten H, Aardal S, Hevrøy O. Improved oxygenation using the prone position in patients with ARDS. Acta Anaesthesiol Scand 1998;42(3):329-334.

85. Jolliet $\mathrm{P}$, Bulpa $\mathrm{P}$, Chevrolet JC. Effect of the prone position on gas exchange and hemodynamics in severe acute respiratory distress syndrome. Crit Care Med 1998;26(12):1977-1985.

86. Papazian L, Paladini MH, Bregeon F, Huiart L, Thirion X, Saux P, et al. Is a short trial of prone positioning sufficient to predict the improvement in oxygenation in patients with acute respiratory distress syndrome? Intensive Care Med 2001;27(6):1044-1049.

87. Venet C, Guyomarc'h S, Migeot C, Bertrand M, Gery P, Page D, et al. The oxygenation variations related to prone positioning during mechanical ventilation: a clinical comparison between ARDS and non-ARDS hypoxemic patients. Intensive Care Med 2001;27(8): 1352-1359.

88. McAuley DF, Giles S, Fichter H, Perkins GD, Gao F. What is the optimal duration of ventilation in the prone position in acute lung injury and acute respiratory distress syndrome? Intensive Care Med 2002;28(4):414-418.

89. L'Her E, Renault A, Oger E, Robaux MA, Boles JM. A prospective survey of early 12-h prone positioning effects in patients with acute respiratory distress syndrome. Intensive Care Med 2002;28(5):570575.

90. Easby J, Abraham BK, Bonner SM, Graham S. Prone ventilation following witnessed pulmonary aspiration: the effect on oxygenation. Intensive Care Med 2003;29(12):2303-2306.

91. Gainnier M, Michelet P, Thirion X, Arnal JM, Sainty JM, Papazian L. Prone position and positive end-expiratory pressure in respiratory distress syndrome. Crit Care Med 2003;31(12):2719-2726.

92. Reutershan J, Schmitt A, Dietz K, Unertl K, Fretschner R. Alveolar recruitment during prone position: times matters. Clin Sci 2006; 110(6):655-663.

93. Charron C, Repesse X, Bouferrache K, Bodson L, Castro S, Page B, et al. $\mathrm{P}_{\mathrm{aCO}_{2}}$ and alveolar dead space are more relevant than $\mathrm{P}_{\mathrm{aO}_{2}} / \mathrm{F}_{\mathrm{IO}_{2}}$ ratio in monitoring the respiratory response to prone position in ARDS patients: a physiological study. Crit Care 2011;15(4):R175.

94. Hale DF, Cannon JW, Batchinsky AI, Cancio LC, Aden JK, White $\mathrm{CE}$, et al. Prone positioning improves oxygenation in adult burn patients with severe acute respiratory distress syndrome. J Trauma Acute Care Surg 2012;72(6):1634-1639.

95. Lee K, Kim MY, Yoo JW, Hong SB, Lim CM, Koh Y. Clinical meaning of early oxygenation improvement in severe acute respiratory distress syndrome under prolonged prone positioning. Korean J Intern Med 2010;25(1):58-65.

96. Vieillard-Baron A, Charron C, Caille V, Belliard G, Page B, Jardin F. Prone positioning unloads the right ventricle in severe ARDS. Chest 2007;132(5):1440-1446.

97. Nakos G, Tsangaris I, Kostanti E, Nathanail C, Lachana A, Koulouras V, Kastani D. Effect of the prone position with hydrostatic pulmonary edema compared with patients with acute respiratory distress syndrome and pulmonary fibrosis. Am J Respir Crit Care Med 2000;161(2):360-368.

98. Romero CM, Cornejo RA, Gálvez LR, Llanos OP, Tobar EA, Berasaín MA, et al. Extended prone position ventilation in severe acute respiratory distress syndrome: a pilot feasibility study. J Crit Care 2009;24(1):81-88.

99. Bajwa AA, Arasi L, Canabal JM, Kramer DJ. Automated prone positioning and axial rotation in critically ill, nontrauma patients with acute respiratory distress syndrome (ARDS). J Intensive Care Med 2010;25(2):121-125. 


\section{PRONe Position IN ARDS}

100. Reinprecht A, Greher M, Wolfsberger S, Dietrich W, Illievich UM, Gruber A. Prone position in subarachnoid hemorrhage patients with acute respiratory distress syndrome: effects on cerebral tissue oxygenation and intracranial pressure. Crit Care Med 2003;31(6): 1831-1838.

101. Nekludov M, Bellander BM, Mure M. Oxygenation and cerebral perfusion pressure improved in the prone position. Acta Anaesthesiol Scand 2006;50(8):932-936.

102. Varpula T, Jousela I, Niemi R, Takkunen O, Pettilä V. Combined effects of prone positioning and airway pressure release ventilation on gas exchange in patients with acute lung injury. Acta Anaesthesiol Scand 2003;47(5):516-524.

103. Cornejo RA, Díaz JC, Tobar EA, Bruhn AR, Ramos CA, Gonzáles $\mathrm{RA}$, et al. Effect of prone positioning on lung protection in patients with acute respiratory distress syndrome. Am J Respir Crit Care Med 2013;188(4):440-448.

104. Protti A, Chiumello D, Cressoni M, Carlesso E, Mietto C, Berto V, et al. Relationship between gas exchange response to prone position and lung recruitability during acute respiratory failure. Intensive Care Med 2009;35(6):1011-1017.

105. De Jong A, Molinari N, Sebbane M, Prades A, Futier E, Jung B, et al. Feasibility and effectiveness of prone position in morbidly obese patients with ARDS. Chest 2013;143(6):1554-1561.

106. Curley MA, Thompson JE, Arnold JH. The effect of early and repeated prone positioning in pediatric patients with acute lung injury. Chest 2000;118(1):156-163.

107. Relvas MS, Silver PC, Sagy M. Prone positioning of pediatric patients with ARDS results in improvement in oxygenation if maintained for $>12$ h daily. Chest 2003;124(1):269-274.

108. Casado-Flores J, Martínez de Azagra A, Ruiz-López MJ, Ruiz M, Serrano A. Pediatric ARDS: effect of supine-prone postural changes on oxygenation. Intensive Care Med 2002;28(12):1792-1976.

109. Kornecki A, Frndova H, Coates AL, Shemie SD. 4A randomized trial of prolonged prone positioning in children with acute respiratory failure. Chest 2001;119(1):211-218.

110. Martin RJ, Herrell N, Rubin D, Fanaroff A. Effect of supine and prone positions on arterial oxygen tension in the preterm infant. Pediatrics 1979;63(4):528-531.

111. Wagaman MJ, Shutack JG, Moomjian AS, Schwartz JG, Shaffer TH, Fox WW. Improved oxygenation and lung compliance with prone positioning of neonates. J Pediatr 1979;94(5):787-791.

112. Eghbalian F. A comparison of supine and prone positioning on improving arterial oxygenation in premature neonates. J Neonatal Perinatal Med 2014;7(4):273-277.

113. Brüssel T, Hachenberg T, Roos N, Lemzem H, Konertz W, Lawin P. Mechanical ventilation in the prone position for acute respiratory failure after cardiac surgery. J Cardiothorac Vasc Anesth 1993;7(5): 541-546.

114. Watanabe I, Fujihara H, Sato K, Honda T, Ohashi S, Endoh H, et al. Beneficial effect of a prone position for patients with hypoxemia after transthoracic esophagectomy. Crit Care Med 2002;30(8):17991802.

115. Reignier J, Lejeune O, Renard B, Fiancette M, Lebert C, Bontemps F, et al. Short-terms effects of prone position in chronic obstructive pulmonary disease patients with severe acute and hypercapnic respiratory failure. Intensive Care Med 2005;31(8):1128-1131.

116. Pelosi P, Brazzi L, Gattinoni L. Prone position in acute respiratory distress syndrome. Eur Respir J 2002;20(4):1017-1028.

117. Gattinoni L, Tognoni G, Pesenti A, Taccone P, Mascheroni D, Labarta V, et al. Effect of prone positioning on the survival of patients with acute respiratory distress syndrome. N Engl J Med 2001;345(8):568-573.

118. Guerin C, Gaillard S, Lemasson S, Ayzac L, Girard R, Beuret P, et al. Effects of systematic prone positioning in hypoxemic acute respiratory failure: a randomized controlled trial. JAMA 2004; 292(19):2379-2387.

119. Fernandez R, Trenchs X, Klamburg J, Castedo J, Serrano JM, Besso $\mathrm{G}$, et al. Prone positioning in acute respiratory distress syndrome: a multicenter randomized clinical trial. Intensive Care Med 2008; 34(8):1487-1491.

120. Curley MA, Hibberd PL, Fineman LD, Wypij D, Shih MC, Thompson JE, et al. Effect of prone positioning on clinical outcomes in children with acute lung injury: a randomized controlled trial. JAMA 2005;294(2):229-237.

121. Charron C, Bouferrache K, Caille V, Castro S, Aegerter P, Page B, et al. Routine prone positioning in patients with severe ARDS: feasibility and impact on prognosis. Intensive Care Med 2011;37(5): 785-790.

122. Kallet RH. Pressure-volume curves in the management of acute respiratory distress syndrome. Respir Care Clin N Am 2003;9(3): 321-341.

123. Kallet RH. Measuring dead-space in acute lung injury. Minerva Anestesiol 2012;78(11):1297-1305.

124. Galiatsou E, Kostanti E, Svarna E, Kitsakos A, Koulouras V, Efremidis SC, Nakos G. Prone position augments recruitment and prevents alveolar overinflation in acute lung injury. Am J Respir Crit Care Med 2006;174(2):187-197.

125. Legras A, Dequin PF, Hazouard E, Doucet O, Tranquart F, Perrotin D. Right-to-left shunt in ARDS: dramatic improvement in prone position. Intensive Care Med 1999;25(4):412-414.

126. Gattinoni L, Vagginelli F, Carlesso E, Taccone P, Conte V, Chiumello $\mathrm{D}$, et al. Decrease in $\mathrm{P}_{\mathrm{aCO}}$, with prone position is predictive of improved outcome in acute respiratory distress syndrome. Crit Care Med 2003;31(12):2727-2733.

127. Piedalue F, Albert RK. Prone positioning in acute respiratory distress syndrome. Respir Care Clin N Am 2003;9(4):495-509.

128. Mackenzie CF. Anatomy, physiology and pathology of the prone position and postual drainage. Crit Care Med 2001;29(5):10841085.

129. Beuret P. Prone position for the prevention of lung infection. Minerva Anestesiol. 2002;68(4):266-268.

130. Mentec H, Dupont H, Bocchetti M, Cani P, Ponche F, Bleichner G. Upper digestive intolerance during enteral nutrition in critically ill patients: frequency, risk factors, and complications. Crit Care Med 2001;29(10):1955-1961.

131. Beuret P, Carton MJ, Nourdine K, Kaaki M, Tramoni G, Ducreux JC. Prone position as a prevention of lung injury in comatose patients: a prospective, randomized, controlled study. Intensive Care Med 2002;28(5):564-569.

132. Voggenreiter G, Aufmkolk M, Stiletto RJ, Baacke MG, Waydhas $\mathrm{C}$, Ose $\mathrm{C}$, et al. Prone position improves oxygenation in posttraumatic lung injury: a prospective randomized trial. J Trauma 2005;59(2):333-341; discussion 341-343.

133. Mancebo J, Fernández R, Blanch L, Rialp G, Gordo F, Ferrer M, et al. A multicenter trial of prolonged prone ventilation in severe acute respiratory distress syndrome. Am J Respir Crit Care Med 2006;173(11):1233-1239.

134. Mounier R, Adrie C, Français A, Garrouste-Orgeas M, Cheval C, Allaouchiche B, et al. Study of prone positioning to reduce ventilator-associated pneumonia in hypoxaemic patients. Eur Respir J 2010;35(4):795-804.

135. Constantin JM, Cayot-Constantin S, Roszyk L, Futier E, Sapin V, Dastugue B, et al. Response to recruitment maneuver influences net alveolar fluid clearance in acute respiratory distress syndrome. Anesthesiology 2007;106(5):944-951.

136. Knight DJW, Mahajan RP. Patient positioning in anesthesia. Cont Ed Anaesth Crit Care Pain 2004;4(5):160-163. 


\section{PRONe Position IN ARDS}

137. Kallet RH, Katz JA, Pittet JF, Ghermey J, Siobal M, Alonso JA, Marks JD. Measuring intraesophageal pressure to assess transmural pulmonary arterial occlusion pressure in patients with clinical acute lung injury: a case series report and review. Respir Care 2000; 45(9):1072-1084.

138. Shimizu M, Fujii H, Yamawake N, Nishizaki M. Cardiac function changes with switching from the supine to prone position: analysis by quantitative semiconductor gated single photon emission computed tomography. J Nucl Cardiol 2015;22(2):301-307.

139. Michelet P, Roch A, Gainnier M, Sainty JM, Auffray JP, Papazian L. Influence of support on intra-abdominal pressure, hepatic kinetics of indocyanine green and extravascular lung water during prone positioning in patients with ARDS: a randomized crossover study. Crit Care 2005;9(3):R251-R257.

140. Hering R, Wrigge H, Vorwerk R, Brensing KA, Schröder S, Zinserling $\mathrm{J}$, et al. The effects of prone positioning on intraabdominal pressure and cardiovascular and renal function in patients with acute lung injury. Anesth Analg 2001;92(5):1226-31.

141. Hering R, Vorwerk R, Wrigge H, Zinserling J, Schroder S, von Spiegel T, et al. Prone positioning, systemic hemodynamics, hepatic indocyanine green kinetics, and gastric intramucosal energy balance in patients with acute lung injury. Intensive Care Med 2002;28(1):53-58.

142. Matejovic M, Rokyta R Jr, Radermacher P, Krouzecky A, Sramek $\mathrm{V}$, Novak I. Effect of prone position on hepato-splanchnic hemodynamics in acute lung injury. Intensive Care Med 2002;28(12): 1750-1755.

143. Moloney ED, Evans TW. Pathophysiology and pharmacological treatment of pulmonary hypertension in acute respiratory distress syndrome. Eur Respir J 2003;21(4):720-727.

144. Marhong J, Fan E. Carbon dioxide in the critically-ill: too much or too little of a good thing? Respir Care 2014;59(10):1597-1605.

145. Curley GF, Laffey JG. Acidosis in the critically ill: balancing risks and benefits to optimize outcome. Crit Care 2014;18(2):129.

146. Tomashefski JF Jr, Davies P, Boggis C, Greene R, Zapol WM, Reid LM. The pulmonary vascular leisions of the adult respiratory distress syndrome. Am J Pathol 1983;112(1):112-126.

147. Vieillard-Baron A, Price LC, Matthay MA. Acute cor pulmonale in ARDS. Intensive Care Med 2013;39(10):1836-1838.

148. Boissier F, Katsahian S, Razazi K, Thille AW, Roche-Campo F, Leon R, et al. Prevalence and prognosis of cor pulmonale during protective ventilation for acute respiratory distress syndrome. Intensive Care Med 2013;39(10):1725-1733.

149. Vieillard-Baron A, Charron C, Caille V, Belliard G, Page B, Jardin F. Prone positioning unloads the right ventricle in severe ARDS. Chest 2007;132(5):1440-1146.

150. Mekontso Dessap A, Boissier F, Leon R, Carreira S, Campo FR, Lemaire F, Brochard L. Prevalance and prognosis of shunting across patent foremen ovale during acute respiratory distress syndrome. Crit Care Med 2010;38(9):1786-1792.

151. Perchiazzi G, Rylander C, Vena A, Derosa S, Polieri D, Fiore T, et al. Lung stress and strain as a function of posture and ventilatory mode. J Appl Physiol 2011;110(5):1374-1383.

152. Broccard AF, Shapiro RS, Schmitz LL, Ravenscraft SA, Marini JJ. Influence of prone position on the extent and distribution of lung injury in a high tidal volume oleic acid model of acute respiratory distress syndrome. Crit Care Med 1997;25(1):16-27.

153. Nishimura M, Honda O, Tomiyama N, Johkoh T, Kagawa K, Nishida T. Body position does not influence the location of ventilatorinduced lung injury. 2000;26(11):1664-1669.

154. Valenza F, Guglielmi M, Maffioletti M, Tedesco C, Maccagni P, Fossali T, et al. Prone position delays the progression of ventilatorinduced lung injury in rats: does lung strain distribution play a role? Crit Care Med 2005;33(2):361-367.
155. Nakos G, Batistatou A, Galiatsou E, Konstanti E, Koulouras V, Kanavaros P, et al. Lung and end organ injury due to mechanical ventilation in animals: comparison between prone and supine positions. Crit Care 2006;10(1):R38-R39.

156. Santana MCE, Garcia CSNB, Xisto DG, Nagato LKS, Lassance RM, Prota LFM, et al. Prone position prevents regional alveolar hyperinflation and mechanical stress and strain in mild experimental acute lung injury. Respir Physiol Neurobiol 2009;167(2):181188.

157. Villar J, Blanco J, Zhang H, Slutsky AS. Ventilator-induced lung injury and sepsis: two sides of the same coin? Minerva Anestesiol 2011;77(6):647-653.

158. Vincent JL, Zambon M. Why do patients who have acute lung injury/acute respiratory distress syndrome die from multiorgan dysfunction syndrome? Implications for management. Clin Chest Med 2006;27(4):725-731; abstract x-xi.

159. Papazian L, Gainnier M, Marin V, Donati S, Arnal JM, Demory D, et al. Comparison of prone positioning and high-frequency oscillatory ventilation in patients with acute respiratory distress syndrome. Crit Care Med 2005;33(10):2162-2171.

160. Kotani M, Kotani T, Ishizaka A, Fujishima S, Koh H, Tasaka S, et al. Neutrophil depletion attenuates interleukin- 8 production in mild-overstretch ventilated normal rabbit lung. Crit Care Med 2004; 32(2):514-519.

161. Chan MC, Hsu JY, Liu HH, Lee YL, Pong SC, Change LY, et al. Effects of prone position on inflammatory markers in patients with ARDS due to community-acquired pneumonia. J Formos Med AsSoc 2007;106(9):708-716.

162. Antunes G, Evans SA, Lordan JL, Frew AJ. Systemic cytokine levels in community-acquired pneumonia and their association with disease severity. Eur Respir J 2002;20(4):990-995.

163. Bhandari V. Developmental differences in the role of interleukins in hyperoxic lung injury in animal models. Front Biosci 2002; 7(12):d1624-d1633.

164. Taccone P, Pesenti A, Latini R, Polli F, Vagginelli F, Mietto C, et al. Prone positioning in patients with moderate and severe acute respiratory distress syndrome. JAMA 2009;302(18):1977-1984.

165. Burdet L, Liaudet L, Schaller MD, Broccard AF. Bilateral breast necrosis after prone position ventilation. Intensive Care Med 2001; 27(8):1435.

166. Girard R, Baboi L, Ayzac L, Richard JC, Guérin C, Proseva Study Group. The impact of patient positioning on pressure ulcers in patients with severe ARDS: results from a multicentre randomized controlled trial on prone positioning. Intensive Care Med 2014; 40(3):397-403.

167. Weig T, Schubert MI, Gruener N, Dolch ME, Frey L, Miller J, et al. Abdominal obesity and prolonged prone positioning increase risk of developing sclerosing cholangitis in critically ill patients with influenza A-associated ARDS. Eur J Med Res 2012;17:30.

168. Pelosi P, Cadringher P, Bottino N, Panigada M, Carrieri F, Riva E, et al. Sigh in acute respiratory distress syndrome. Am J Respir Crit Care Med 1999;159(3):872-880.

169. Bindslev L, Hedenstierna G, Santesson J, Norlander O, Gram I. Airway closure during anesthesia and its prevention by positive end expiratory pressure. Acta Anaesth Scand 1980;24(3):199-205.

170. Katz JA, Ozanne GM, Zinn SE, Fairley HB. Time course and mechanisms of lung-volume increase with PEEP in acute pulmonary failure. Anesthesiology 1981;54(1):9-16.

171. Naureckas ET, Dawson CA, Gerber BS, Gaver DP 3rd, Gerber HL, Linehan $\mathrm{JH}$, et al. Airway reopening pressure inisolated rat lungs. J Appl Physiol 1994;76(3):1372-1377.

172. Gaver DP 3rd, Samsel RW, Solway J. Effects of surface tension and viscosity on airway reopening. J Appl Physiol 1990;69(1): $74-85$. 


\section{PRONe Position IN ARDS}

173. Pelosi P, Bottino N, Chiumello D, Caironi P, Panigada M, Gamberoni $\mathrm{C}$, et al. Sigh in supine and prone position during acute respiratory distress syndrome. Am J Respir Crit Care Med 2003; 167(4):521-527.

174. Oczenski W, Hormann C, Keller C, Lorenzi N, Kepka A, Schwarz S, Fitzgerald RD. Recruitment maneuvers during prone positioning in patients with acute respiratory distress syndrome. Crit Care Med 2005;33(1):54-61.

175. Rival G, Patry C, Floret N, Navellou JC, Belle E, Capellier G. Prone position and recruitment manoevre: the combined effect improves oxygenation. Crit Care 2011;15(3):R125.

176. Zhou X, Liu D, Long Y, Zhang Q, Cui N, He H, et al. The effect of prone position combined with recruitment maneuvers on outcomes in patients with severe acute respiratory distress syndrome. Zhonghua Nei Ke Za Zhi 2014;53(6):437-441.

177. Kallet RH. Adjunctive therapies during mechanical ventilation: airway clearance techniques, therapeutic aerosols and gases. Respir Care 2013;58(6): 1053-1073.

178. Jolliet P, Bulpa P, Ritz M, Ricou B, Lopez J, Chevrolet JC. Additive beneficial effects of the prone position, nitric oxide, and almitrine bismesylate on gas exchange and oxygen transport in acute respiratory distress syndrome. Crit Care Med 1997;25(5):786794.

179. Papazian L, Bregeon F, Gaillat F, Thirion X, Gainnier M, Gregoire $\mathrm{R}$, et al. Respective and combined effects of prone position and inhaled nitric oxide in patients with acute respiratory distress syndrome. Am J Respir Crit Care Med 1998;157(2):580-585.

180. Martinez M, Diaz E, Joseph D, Villagrá A, Mas A, Fernandez R, Blanch L. Improvement in oxygenation by prone position and nitric oxide in patients with acute respiratory distress syndrome. Intensive Care Med 1999;25(1):29-36.

181. Borelli M, Lampati L, Vascotto E, Fumagalli R, Pesenti A. Hemodynamic and gas exchange response to inhaled nitric oxide and prone positioning in acute respiratory distress syndrome. Crit Care Med 2000;28(8):2707-2712.

182. Rialp G, Betbesé AJ, Pérez-Márquez M, Mancebo J. Short-term effects of inhaled nitric oxide and prone positioning in pulmonary and extrapulmonary acute respiratory distress syndrome. Am J Respir Crit Care Med 2001;164(2):243-249.

183. Briel M, Meade M, Mercat A, Brower RG, Talmor D, Walter SD, et al. Higher vs lower positive end-expiratory pressure in patients with acute lung injury and acute respiratory distress syndrome. JAMA 2010;303(9):865-873.

184. Alhazzani W, Alshahrani M, Jaeschke R, Forel JM, Papazian L, Sevransky J, Meade MO. Neuromuscular blocking agents in acute respiratory distress syndrome: a systematic review and metaanalysis of randomized controlled trials. Crit Care 2013;17(2): R43.

185. Suzumura EA, Figueiró M, Normilio-Silva K, Laranjeira L, Oliveira C, Buehler AM, et al. Effect of alveolar recruitment maneuvers on clinical outcomes in patients with acute respiratory distress syndrome: a systematic review and meta-analysis. Intensive Care Med 2014;40(9):1227-1240.

186. Barbas CSV, de Matos GF, Pincelli MP, da Rosa Borges E, Antunes T, de Barros JM, et al. Mechanical ventilation in acute respiratory failure: recruitment and high positive end-expiratory pressure are necessary. Curr Opin Crit Care 2005;11(1):18-28.

187. Litmathe J, Sucker C, Easo J, Wigger L, Dapunt O. Prone and ECMO: a contradiction per se? Perfusion 2012;27(1):78-82.

188. Otterspoor LC, Smit FH, van Laar TJ, Kesecioglu J, van Dijk D. Prolonged use of extracorporeal membrane oxygenation combined with prone positioning in patients with acute respiratory distress syndrome and invasive aspergillosis. Perfusion 2012;27(4):335-337.
189. Kimmoun A, Guerci P, Bridey C, Ducrocq N, Vanhuyse F, Levy B. Prone positioning use to hasten veno-venous ECMO weaning in ARDS. Intensive Care Med 2013;39(10):1877-1879.

190. Kipping V, Weber-Carstens S, Lojewski C, Feldmann P, Rydlewski A, Boemke W, et al. Prone position during ECMO is safe and improves oxygenation. Int J Artif Organs 2013;36(11):821-832.

191. Guervilly C, Hraiech S, Gariboldi V, Xeridat F, Dizer S, Toesca R, et al. Prone positioning during veno-venous extracorporeal membrane oxygenation for severe acute respiratory distress syndrome in adults. Minerva Anestesiol 2014;80(3):307-313.

192. Masuda Y, Tatsumi H, Imaizumi H, Gotoh K, Yoshida S, Chihara $\mathrm{S}$, et al. Effect of prone positioning on cannula function and impaired oxygenation during extracorporeal circulation. J Artif Organs 2014;17(1):106-109.

193. Goettler CE, Pryor JP, Hoey BA, Phillips JK, Balas MC, Shapiro MB. Prone positioning does not affect cannula function during extracorporeal membrane oxygenation or continuous renal replacement therapy. Crit Care 2002;6(5):452-455.

194. Kredel M, Bischof L, Wurmb TE, Roewer N, Muellenbach RM. Combination of positioning therapy and venovenous extracorporeal membrane oxygenation in ARDS patients. Perfusion 2014;29(2): 171-177.

195. ARDS Definition Taskforce, Ranieri VM, Rubenfeld GD, Thompson BT, Ferguson ND, Caldwell E, et al. Acute respiratory distress syndrome: the Berlin definition. JAMA 2012;307(23): 25262533.

196. Cressoni M, Chiumello D, Carlesso E, Chiurazzi C, Amini M, Brioni $\mathrm{M}$, et al. Compressive forces and computed tomographyderived positive end-expiratory pressure in acute respiratory distress syndrome. Anesthesiology 2014;121(3):572-581.

197. Kallet RH, Branson RD. Do the NIH ARDS clinical trials network $\mathrm{PEEP} / \mathrm{F}_{\mathrm{IO}}$ tables provide the best evidence based guide to balance PEEP and $\mathrm{F}_{\mathrm{IO}_{2}}$ settings in adults? Respir Care 2007;52(4):461-475; discussion $475-477$.

198. Lhéritier G, Legras A, Caille A, Lherm T, Mathonnet A, Frat JP, et al. Prevalence and prognostic value of acute cor pulmonale and patent foramen ovale in ventilated patients with early acute respiratory distress syndrome: a multicenter study. Intensive Care Med 2013;39(10):1734-1742.

199. Schmitt JM, Vieillard-Baron A, Augarde R, Prin S, Page B, Jardin F. Positive end-expiratory pressure titration in acute respiratory distress syndrome patients: impact on right ventricular outflow impedance evaluated by pulmonary artery Doppler flow velocity measurements. Crit Care Med 2001;29(6):1154-1158.

200. Mekontso Dessap A, Charron C, Devaquet J, Aboab J, Jardin F, Brochard L, Vieillard-Baron A. Impact of acute hypercapnia and augmented positive end-expiratory pressure on right ventricle function in severe acute respiratory distress syndrome. Intensive Care Med 2009;35(11):1850-1858.

201. Prone Tutorial. https://www.youtube.com/watch?v $=$ Hd5o4ldp3c0. Accessed June 19, 2015.

202. Prebio M, Katz-Papatheophilou E, Heindl W, Gelbmann H, Burghuber OC. Reduction of pressure sores during prone positioning of ventilated intenseive care patients by the prone-head support system: a pilot study. Wien Klin Wochenschr 2005;117(3):98105.

203. Wenk M, Pöpping D, Henning M, Wenk M, Liljenqvist U, Möllmann M. Creation of a head and face protection device for children undergoing procedures in prone position. Pediatr Anesth 2009;19(6): 587-592.

204. Pape HC, Regel G, Borgmann W, Sturm JA, Tscherne H. The effect of kinetic positioning on lung function and pulmonary haemodynamics in posttraumatic ARDS: a clinical study. Injury 1994;25(1): $51-57$. 


\section{Prone Position In ARDS}

205. Bein T, Reber A, Metz C, Jauch KW, Hedenstierna G. Acute effects of continuous rotational therapy on ventilation-perfusion inequality in lung injury. Intensive Care Med 1998;24(2):132-137.

206. Calaf Tost C, Alvarez García P. Lateralization as an alternative to static prone decubitus in patients with ARDS. Enferm Intensiva 2006;17(1):12-18.

207. Staudinger T, Kofler J, Müllner M, Locker GJ, Laczika K, Knapp $\mathrm{S}$, et al. Comparison of prone position and continuous rotation of patients with acute respiratory distress syndrome: results of a pilot study. Crit Care Med 2001;29(1):51-56.
208. KCI Therapeutic Support Systems. KCI Rotoprone therapy system: frequently asked questions. San Antonio: KCI USA; 2008. pp 1-5.

209. Gattinoni L, D'Andrea L, Pelosi P, Vitale G, Pesenti A, Fumagalli R. Regional effects and mechanism of positive end-expiratory pressure in early adult respiratory distress syndrome. JAMA 1993;269(16): 2122-2127. Erratum in: JAMA 1993; 270(15): 1814.

210. Graf J, Marini JJ. Do airway secretions play an underappreciated role in acute respiratory distress syndrome? Curr Opin Crit Care 2008;14(1):44-49. 